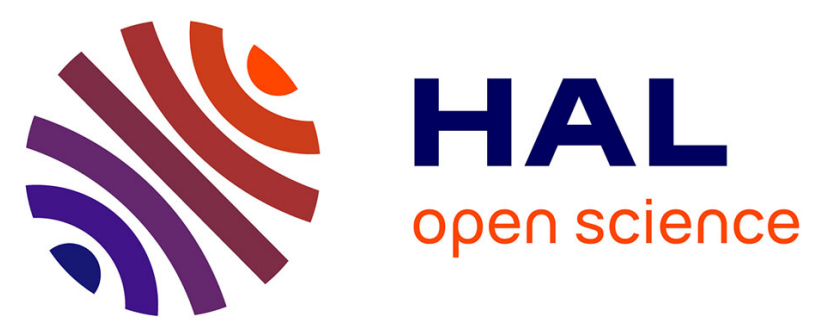

\title{
Complementarity of Density Functional Theory and Nuclear Magnetic Resonance Tools To Probe the Nano-Layered Silicates Surface Chemistry and Morphology
}

Mathilde Poirier, Yannick Millot, Elisa Silva Gomes, Maguy Jaber, Virginie Herledan, Guillaume Laugel, Pierre Micoud, François Martin, Hélène Lauron-Pernot, Hervé Toulhoat

\section{- To cite this version:}

Mathilde Poirier, Yannick Millot, Elisa Silva Gomes, Maguy Jaber, Virginie Herledan, et al.. Complementarity of Density Functional Theory and Nuclear Magnetic Resonance Tools To Probe the Nano-Layered Silicates Surface Chemistry and Morphology. Journal of Physical Chemistry C, 2020, 124 (1), pp.267-286. 10.1021/acs.jpcc.9b05903 . hal-02457727

\section{HAL Id: hal-02457727 \\ https://hal.sorbonne-universite.fr/hal-02457727}

Submitted on 28 Jan 2020

HAL is a multi-disciplinary open access archive for the deposit and dissemination of scientific research documents, whether they are published or not. The documents may come from teaching and research institutions in France or abroad, or from public or private research centers.
L'archive ouverte pluridisciplinaire HAL, est destinée au dépôt et à la diffusion de documents scientifiques de niveau recherche, publiés ou non, émanant des établissements d'enseignement et de recherche français ou étrangers, des laboratoires publics ou privés. 


\section{Complementarity of Density Functional Theory and Nuclear Magnetic Resonance Tools}

To Probe the Nano-Layered Silicates Surface Chemistry and Morphology

Mathilde Poirier ${ }^{1 *}$, Yannick Millot ${ }^{2}$, Elisa Silva Gomes ${ }^{2}$, Maguy Jaber ${ }^{3}$, Virginie Herledan², Guillaume Laugel $^{2}$, Pierre Micoud ${ }^{1}$, François Martin ${ }^{1}$, Hélène Lauron-Pernot ${ }^{2}$ and Hervé Toulhoat $^{2 *}$

${ }^{1}$ ERT Géomatériaux, GET, Université de Toulouse, CNRS, IRD, UPS, 14 Avenue Edouard Belin, 31400 Toulouse, France

${ }^{2}$ Laboratoire de Réactivité de Surface UMR 7197 Sorbonne Université-CNRS, UPMC, 4 Place Jussieu ; 75005 Paris, France

${ }^{3}$ Laboratoire d'Archéologie Moléculaire et Structurale, Institut Universitaire de France, UMR 8220 Sorbonne Université-CNRS, UPMC, 4 Place Jussieu ; 75005 Paris, France

* mathilde.1.poirier@gmail.com; (+33)787038049

* herve.toulhoat@orange.fr; (+33)672766554 


\section{ABSTRACT}

By combining experimental spectroscopic, structural and physical characterizations, and extensive Density Functional Theory (DFT) simulations, unprecedented insight is gained on the local surface properties of synthetic talc nanoparticles, their structure, morphology and particle size distribution. Basically, the Nuclear Magnetic Resonance (NMR) chemical shifts profiles of these nano-layered silicates were dissected thoroughly and revealed the existence of bulk and surface contributions in the ${ }^{1} \mathrm{H}$ and ${ }^{29} \mathrm{Si}$ spectra. Beyond the fact that a significant knowledge has been acquired on the overall structure of the synthetic talc nanoparticles (mixture of defective and non-defective layers, with defects rejected on the external interfaces), the highlighting of these signals enabled to access the average morphologies and particle sizes of the samples by decomposing the ${ }^{29} \mathrm{Si}$ NMR profiles into Lorentzian contributions. Finally, the particle size distributions in number were also described in terms of a Log-normal law. These distributions were compared to the particle sizes obtained from X-ray Diffraction (XRD), Brunauer-Emmett-Teller measurements (BET) and Dynamic Light Scattering (DLS) methods. The distributions of gyration radii determined by DLS are shown to match the distributions in size in consistence with the same morphology.

\section{INTRODUCTION}

Nano-sized minerals, i.e. particles of size no larger than a few tens of nanometers, have peculiar physicochemical properties compared to larger-scale minerals. These properties arise from their great proportion of surface environments that generate unexpected chemical reactivity, mechanical behaviors, and electronic or molecular structures. ${ }^{1-3}$

Among all of the examples evidencing the role of the particle size on the physicochemical behavior of a mineral, ${ }^{4-7}$ the case of "talc", a layered magnesium silicate with 
$\mathrm{Si}_{4} \mathrm{Mg}_{3} \mathrm{O}_{10}(\mathrm{OH})_{2}$ as chemical formula per half unit cell is particularly remarkable. It has indeed been noticed that the passage from micron-sized talc particles (natural particles) to nano-sized talc particles (synthetic particles) enabled to disrupt their usual physicochemical properties as the particles became hydrophilic and highly reactive towards charged organic molecules. ${ }^{8,9}$ This was evidenced by Dumas and co-workers ${ }^{10,11}$ who managed to synthetize hydrophilic talc particles of tunable nano-sizes by undergoing a hydrothermal route in sub- and supercritical conditions. Compared to natural micron-sized particles, the synthetic particles present also the theoretical advantage of being almost pure from a chemical and mineralogical point of view since neither cation substitutions nor other mineral phases occur in principle during the synthesis except for traces. The design of such particles thereby paved the way to new domains of applications, such as in the fields of polymers ${ }^{12-16}$ and cosmetics (14 patents registered by L’Oréal). ${ }^{17}$

A deep understanding of the surface chemistry of nano-layered silicates is highly necessary for scientific and industrial purposes. In this study, solid-state Nuclear Magnetic Resonance (NMR) spectroscopies such as ${ }^{1} \mathrm{H}$ and ${ }^{29} \mathrm{Si}$ were used to probe the molecular structure of synthetic talc nanoparticles. The minute size and synthetic character of the nanomineral are here essential parameters because they allow to enhance the signals of surface species and enable to prevent the broadening of the NMR spectra due to paramagnetic impurities in natural materials ${ }^{18-22}$. For example, Dumas et al., 2013, 2016 identified two additional contributions in the ${ }^{1} \mathrm{H}$ NMR spectrum of synthetic talc compared to natural talc at $+1.8 \mathrm{ppm}$ and $+4.0 \mathrm{ppm}$, as well as one in ${ }^{29} \mathrm{Si} \mathrm{NMR}$ at $-95 \mathrm{ppm}$. The authors attributed them respectively to silanols groups, adsorbed water, and $\mathrm{Q}^{2}$-type species, thus in relation with the amount of lateral sheet edges. However, further work presented here, as one-dimensional and two-dimensional NMR analyses, revealed the presence of some inconsistencies in this primary interpretation, but no obvious alternative assignations could be proposed in return. 
In order to overcome this impasse, Density Functional Theory (DFT) calculations were performed to help the interpretation of the experimental results. DFT is a powerful technique that enables to simulate the theoretical NMR chemical shifts of atoms belonging to a mineral structure according to their local environment. In this way, DFT allowed us to make an assignation of the experimental chemical shifts in terms of local structures by comparison with theoretical predictions from first principles. Moreover, some structural hypotheses concerning the surface chemistry of nano-layered silicates were screened by examining the types of configurations that are energetically favored in some bulk and surface atomistic models. Finally, taking advantage of the equilibrium morphology of talc nanoparticles in presence of liquid water and synthesis temperature previously determined theoretically by some of us, the assignation of NMR signals to well-defined species belonging to expressed surfaces of various Miller indices allowed a quantitative interpretation of the experimental NMR spectra in terms of average sizes and morphologies of the nanocrystallites. This interpretation was compared to the information provided by Debye-Scherrer analysis of (001) X-ray diffraction (XRD) lines, by Brunauer-Emmett-Teller (BET) surface area measurements, and by Dynamic Light Scattering (DLS): we show for the first time how to reconcile the four approaches.

To sum up, this article aims at showing unprecedented information on morphology and surface chemistry of nano-layered silicates by combining NMR spectroscopy and DFT calculations.

\section{EXPERIMENTAL SECTION}

Preparation of a Series of Nano-Sized Talc Samples. All chemical products were purchased from Sigma Aldrich and five nano-sized talc samples were synthetized as followed: 0.1 mole of sodium metasilicate pentahydrate $\left(\mathrm{Na}_{2} \mathrm{SiO}_{3} .5 \mathrm{H}_{2} \mathrm{O}, \geq 97 \%\right)$ and 0.075 mole of magnesium acetate tetrahydrate $\left(\left(\mathrm{CH}_{3} \mathrm{COO}\right)_{2} \mathrm{Mg} .4 \mathrm{H}_{2} \mathrm{O}, \geq 98 \%\right)$ were dissolved respectively in $80 \mathrm{~mL}$ of 
deionized water (beaker $\mathrm{A}$ ) and $50 \mathrm{~mL}$ of $1 \mathrm{~N}$ acid acetic $\geq 99 \%$ (beaker $\mathrm{B}$ ). $50 \mathrm{~g}$ of anhydrous sodium acetate $\left(\mathrm{CH}_{3} \mathrm{COONa}, \geq 99 \%\right)$ were added in beaker $\mathrm{A}$. The two beakers were then mixed together to form a white precipitate: An amorphous talc precursor. The total volume was completed to $210 \mathrm{~mL}$ with deionized water. The crystallization of the talc precursor into pristine talc particles was performed in a stainless steel autoclave under hydrothermal conditions at $300^{\circ} \mathrm{C}, 86$ bar for a variable time. The as-produced gel of nano-sized talc particles was then washed 4 times to remove the excess of sodium acetate salts. Each washing consisted in dispersing the talc gel in $700 \mathrm{~mL}$ of deionized water, then centrifuging it at $13000 \mathrm{rpm}$ during 30 min and removing the Na-enriched supernatant. According to elemental analysis performed for typical sample, each washing step divided the residual $\mathrm{Na}$ content by a factor about 3 , so that this procedure allowed $95 \%$ removal of residual sodium acetate. The washing efficiency declined beyond 4 steps. Five samples were prepared in this way by tailoring the hydrothermal synthesis duration to vary their crystallinity and particle size. They are referred to as ST-2H, ST-6H, ST-1D, ST-2W and ST-1M for synthetic talcs (ST) of 2 hours, 6 hours, 1 day, 2 weeks and 1 month of synthesis respectively. Noteworthy that another sample prepared in the same conditions than ST-6H was washed only 3 times instead of 4 to increase the proportion of sodium acetate in the sample. It is referred to as ST-AcONa.

Separation of the fine and coarse fractions was achieved by centrifuging a ST gel of 2 weeks of synthesis at $12000 \mathrm{rpm}$ during 1 hour. The centrifugation enabled to separate the particles in relation to their sizes (large particles at the bottom of the pot; small particles on the top). The efficiency of the separation was controlled by XRD and DLS measurements. The fine fraction exhibits a particle size of $47 \mathrm{~nm}$ while the coarser one of $473 \mathrm{~nm}$ (both determined by DLS, D50 values). The two products were dried at $110^{\circ} \mathrm{C}$ for analysis and given the names of ST-2W-F and ST-2W-C for the fine and coarse fractions respectively. 
X-ray Diffraction Analyses. Diffractograms were recorded on disoriented talc powders using a Bruker D2 Phaser diffractometer operating under the reflection of the $\mathrm{CuK} \alpha_{1+2}$ radiation (GET laboratory, Toulouse, France). Measurements were performed over the $0-80^{\circ} 2 \theta$ range, with a step size of $0.02^{\circ} 2 \theta$ and a count time per step of $0.5 \mathrm{~s}$. The analysis of this data performed thanks to the fytik 1.3.1 software (http://fytik.nieto.pl) allowed the determination of $d$ spacing values with an accuracy of the order of $10^{-3} \mathrm{~nm}$.

Dynamic Light Scattering Analyses. DLS was used to determine the size of the particles in their colloidal form. Preparation consisted in dispersing $0.5 \mathrm{~g}$ of synthetic talc gel in $20 \mathrm{~mL}$ of deionized water under magnetic stirring and ultrasounds during $1 \mathrm{~min}$. Measurements were recorded on a Cordouan Technology VASCO-2 at the GET laboratory of Toulouse (France). A statistical analysis was performed on each sample using the multi-acquisition mode of the NanoQ software of VASCO to get information on their size dispersion. All of the samples were measured 20 times during $60 \mathrm{~s}$ (for ST-2H, ST-6H and ST-1D) or $120 \mathrm{~s}$ (for ST-2W and ST1M). The correlogram acquisitions were processed by the Padé-Laplace inversion algorithm. The precision on average size measurements by this technique is $2 \%$, compliant with the International Standard ISO13321.

Solid-State NMR. ${ }^{1} \mathrm{H}$ and ${ }^{29} \mathrm{Si}$ direct polarization solid-state NMR spectra were recorded on a Bruker Avance III $400 \mathrm{MHz}$ spectrometer in a static field of 9.4 T (LCC laboratory, Toulouse, France). All chemical shifts are relative to tetramethylsilane (TMS). Measurements were performed on synthetic talc powders in $\mathrm{ZrO}_{2}$ rotors. The ${ }^{1} \mathrm{H}$ NMR experiments were obtained using a $1.3 \mathrm{~mm}$ probe operating at $399.6 \mathrm{MHz}$ and the rotors were spun at $45 \mathrm{kHz}$ to attenuate the dipolar coupling effects. Compared to usual $12.5 \mathrm{kHz}$ and $4 \mathrm{~mm}$ probe diameter MAS rotors, we do not expect very large temperature differences induced by frictional effects. Indeed, literature reports rotor temperatures around $35^{\circ} \mathrm{C}$ and $45^{\circ} \mathrm{C}$ respectively ${ }^{52,53}$. The spectra were recorded using a small flip angle of $30^{\circ}$ (RF impulsion of $1.15 \mu \mathrm{s}$ ), with 8 accumulations and a 
recycle delay of $5 \mathrm{~s}$. The ${ }^{29} \mathrm{Si}$ NMR experiments were obtained using a $4 \mathrm{~mm}$ probe operating at $79.39 \mathrm{MHz}$. Rotors were spun at $8 \mathrm{kHz}$ and the spectra were recorded under high-power proton decoupling conditions using a small flip angle of $30^{\circ}$ (RF impulsion of $3 \mu$ s), with 960 accumulations and a recycle delay of $60 \mathrm{~s}$.

${ }^{23} \mathrm{Na}$ direct polarization and two dimensions (2D) experiments were obtained using a Bruker Avance spectrometer operating in a static field of 11.7 T (LRS, Paris, France). The resonance frequency of ${ }^{1} \mathrm{H},{ }^{23} \mathrm{Na},{ }^{13} \mathrm{C}$ and ${ }^{29} \mathrm{Si}$ were $500.16,132.30,125.77$ and $99.36 \mathrm{MHz}$, respectively. A Bruker $4 \mathrm{~mm}$ standard and triple channels MAS probes were used to perform all the experiments at a spinning speed of $12.5 \mathrm{kHz}$. The ${ }^{1} \mathrm{H},{ }^{23} \mathrm{Na},{ }^{13} \mathrm{C}$ and ${ }^{29} \mathrm{Si}$ chemical shifts were referenced to external standards of TMS, $\mathrm{NaCl}$ aqueous solution (1M), adamantane and TMS, respectively. ${ }^{23} \mathrm{Na}$ direct polarization MAS NMR spectra were recorded by small-flipangle technique with a pulse of $1 \mu \mathrm{s}(\pi / 8), 3 \mathrm{~s}$ for the recycle delay and 1024 accumulations.

The 2D $\left\{{ }^{1} \mathrm{H}\right\}-{ }^{13} \mathrm{C}$ HETCOR (HETeronuclear CORrelation) MAS NMR spectra with $\mathrm{CP}$ polarization transfer were acquired with $3.5 \mu$ s for proton $90^{\circ}$ pulse duration, a contact time and recycle delay of $2 \mathrm{~ms}$ and $2 \mathrm{~s}$, respectively. We used $48 \mathrm{t}_{1}$ increments of $80 \mu \mathrm{s}$ for F1 dimension acquisition and 2048 scans. The $\left\{{ }^{1} \mathrm{H}\right\}-{ }^{29}$ Si HETCOR MAS NMR spectra with CP polarization transfer were acquired with $3.3 \mu$ s for proton $90^{\circ}$ pulse duration, a contact time and recycle delay of $3 \mathrm{~ms}$ and $2 \mathrm{~s}$, respectively. We used $160 \mathrm{t}_{1}$ increments of $40 \mu \mathrm{s}$ for F1 dimension acquisition and 640 scans.

The 2D $\left\{{ }^{29} \mathrm{Si}\right\}-{ }^{23} \mathrm{Na} \mathrm{D}-\mathrm{HMQC}$ (Dipolar-Heteronuclear Multiple-Quantum Coherence) MAS NMR experiments were obtained with rf nutation frequencies of 8 and $25 \mathrm{kHz}$ for ${ }^{23} \mathrm{Na}$ and ${ }^{29} \mathrm{Si}$, respectively. $S R 4_{1}^{2}$ was used as the recoupling sequence to re-introduce ${ }^{23} \mathrm{Na}^{29} \mathrm{Si}$ dipolar interaction with a rf field strength of $25 \mathrm{kHz}(=2 * v$ rot $)$ during $2880 \mu \mathrm{s}$. Spectra result 
from averaging 12000 transients for each of $66 t_{1}$ increments with $t_{1}=25 \mu$ s and a recycle delay of $0.25 \mathrm{~s}$.

The 2D $\left\{{ }^{1} \mathrm{H}\right\}-{ }^{23} \mathrm{Na}$ D-HMQC MAS NMR experiments were obtained with rf nutation frequencies of 8 and $80 \mathrm{kHz}$ for ${ }^{23} \mathrm{Na}$ and ${ }^{1} \mathrm{H}$, respectively. $S R 4_{1}^{2}$ was used as the recoupling sequence to re-introduce ${ }^{23} \mathrm{Na}-{ }^{1} \mathrm{H}$ dipolar interaction with a rf field strength of $25 \mathrm{kHz}(=2 * v$ rot $)$ during $1440 \mu$ s. Spectra result from averaging 6144 transients for each of $50 t_{1}$ increments with $\mathrm{t}_{1}=50 \mu \mathrm{s}$ and a recycle delay of $0.25 \mathrm{~s}$.

\section{COMPUTATIONAL DETAILS}

Density Functional Theory calculations. DFT calculations were performed through the MAPS interface. ${ }^{23}$ The bulk talc structure was recovered as file 9008040. cif $^{24}$ from the Crystallography Open Database. ${ }^{25}$ Total energy calculations were performed with the VASP version 5.4.1 software $^{26}$ within the density functional theory, using projected augmented wavefunctions, the $\mathrm{PBE}$ functiona ${ }^{27}$ in the generalized gradient approximation and periodic boundary conditions. Atomic positions, and eventually unit-cell parameters, were optimized in order to minimize the total energy within the approximation chosen for the various atomistic models considered, taking advantage of symmetries. In all simulations, an energy cutoff of 400 $\mathrm{eV}$ was fixed for the planewave basis set. SCF cycles were converged to $10^{-4} \mathrm{eV}$, and ionic relaxation to $5.10^{-2} \mathrm{eV} . \AA^{-1}$. Van der Waals corrections to the total energy were applied according to the zero damping DFT-D3 method of Grimme. ${ }^{28}$ Brillouin zone sampling was performed according to the automatic generation scheme implemented in VASP, or limited to the gamma point for the larger unit-cells. NMR chemical shifts tensors were computed for previously relaxed models according to the linear response method. ${ }^{29,30}$ Isotropic chemical shifts $\delta$ for ${ }^{1} \mathrm{H},{ }^{29} \mathrm{Si},{ }^{23} \mathrm{Na},{ }^{25} \mathrm{Mg}$ and ${ }^{19} \mathrm{~F}$ nuclei were predicted from calculated on site shielding constants $\sigma$ using the linear correlations obtained with respect to experimental references. Shifts 
are referenced to TMS for ${ }^{29} \mathrm{Si}$ and ${ }^{1} \mathrm{H}, 1 \mathrm{M} \mathrm{NaCl}$ aqueous solution for ${ }^{23} \mathrm{Na}, 1 \mathrm{M} \mathrm{MgSO}_{4}$ aqueous solution for ${ }^{25} \mathrm{Mg}$, and $\mathrm{CFCl}_{3}$ for ${ }^{19} \mathrm{~F}$. Calculated absolute isotropic shielding constants including $\mathrm{G}=0$ contributions for valence and core electrons were systematically considered for these calibrations.

Monte Carlo simulation of liquid water: First, the approximate number of water molecules contained in the liquid state at ambient conditions $\left(55.5\right.$ mol. $\left.\mathrm{l}^{-1}\right)$ in a box of dimensions corresponding to the void of circa $0.59 \mathrm{~nm}^{-3}$ created in a $1 \times 1 \times 2$ talc supercell, i.e. involving 4 TOT layers initially, from which 1 TOT layer has been removed, was estimated at 20. Then, using the "Amorphous Builder" module of the MAPS interface, a configuration of 20 molecules at $300 \mathrm{~K}$ and target density $1.0 \mathrm{~g} . \mathrm{cm}^{-3}$ was obtained through a Monte Carlo simulation in the NVT ensemble generating a cubic periodic box of appropriate side. Intra- and intermolecular interactions were represented by the classical forcefield Dreiding. ${ }^{31}$ The initial configuration thus sampled was relaxed at the DFT-D3 level in the P1 symmetry at fixed unit-cell parameter as described in the previous subsection. The resulting periodic box of 20 water molecules was used to fill the interlayers void in the 3 TOT supercells including various defects Di, for further DFT optimizations.

\section{EXPERIMENTAL RESULTS}

\section{Crystallinity and Particle Size of the Series of Nano-Sized Talc Samples. Talc} $\left(\mathrm{Si}_{4} \mathrm{Mg}_{3} \mathrm{O}_{10}(\mathrm{OH})_{2}\right)$ is a trioctahedral magnesium layered silicate that presents a TOT structure. It is composed of one sheet of $\mathrm{Mg}$ octahedra surrounded by two sheets of Si tetrahedra. In this study, five synthetic talc samples of growing crystallinity were prepared through hydrothermal conditions to investigate the surface chemistry and morphology of nano-layered silicates. The 
as-produced talc particles are well-extended in the $(\mathrm{ab})$ plane and give rise to strong $00 \mathrm{l}$ diffraction lines in XRD (Figure 1). Each sample evidences a typical diffraction pattern of a talc structure, with $d$ spacing values ${ }^{32}$ of about $9.37 \AA$ (001), $4.68 \AA(002)$ and $3.13 \AA$ (003). The results show a gradual increase of crystallinity related to the increase of the hydrothermal duration. In this way, ST-1M obtained after 1 month of hydrothermal treatment displays the most intense and sharpened diffraction lines, with a 001 reflection $\left(\mathrm{d}_{001}=9.37 \AA\right)$ very close to the one encountered in natural talc. On the contrary, ST-2H obtained after only 2 hours of synthesis is much less crystallized since it displays wide and weak diffraction lines, with a 001 reflection shifted by $0.18 \AA\left(\mathrm{d}_{001}=9.55 \AA\right.$ ) compared to ST-1M. ${ }^{10}$ The Rietveld method was tested by a specialized laboratory on a synthetic talc comparable to our ST-2W sample. It failed in view of the asymmetry, low intensity and shift towards low angles of the (001) line. We did not pursue this approach since most of our samples prepared at lower synthesis durations exhibit even less suitable XRD patterns.



Figure 1. X-ray powder diffraction patterns of (a) ST-2H; (b) ST-6H; (c) ST-1D; (d) ST-2W; (e) ST-1M.

In terms of morphology and particle size, the samples can be compared to the ones described by Dumas et al. ${ }^{10}$ who worked on a similar series of nano-sized talc samples elaborated with 
the same protocol. The samples are composed of lamellar platelets whose size increases with the duration of synthesis (Figure S1). This increase is accompanied by an increase in the size dispersion which we expect due to Ostwald ripening occurring during the hydrothermal treatment. This particularity was put to good use further in this paper to study the influence of the particle size on the ${ }^{29} \mathrm{Si}$ NMR spectra of synthetic talc. The particle sizes determined by DLS are listed in Table 1 and confirm the particle growth at the nanoscale. The results are given in number and the particle size distributions data are given in Table S1.

Table 1: Particle size of the series of synthetic talc samples determined by DLS (D50 value).

$\begin{array}{lc}\text { Sample } & \text { Average size }(\mathrm{nm}) \\ \text { ST-2H } & 15 \\ \text { ST-6H } & 20 \\ \text { ST-1D } & 37 \\ \text { ST-2W } & 130 \\ \text { ST-1M } & 171\end{array}$

${ }^{1} \mathrm{H},{ }^{29} \mathrm{Si}$ and ${ }^{23} \mathrm{Na}$ Direct polarization NMR Signature of the Nano-Sized Talc Samples. ${ }^{1} \mathrm{H}$ direct polarization (DP) MAS NMR results of the synthetic talc samples are presented in Figure 2a. 



c)
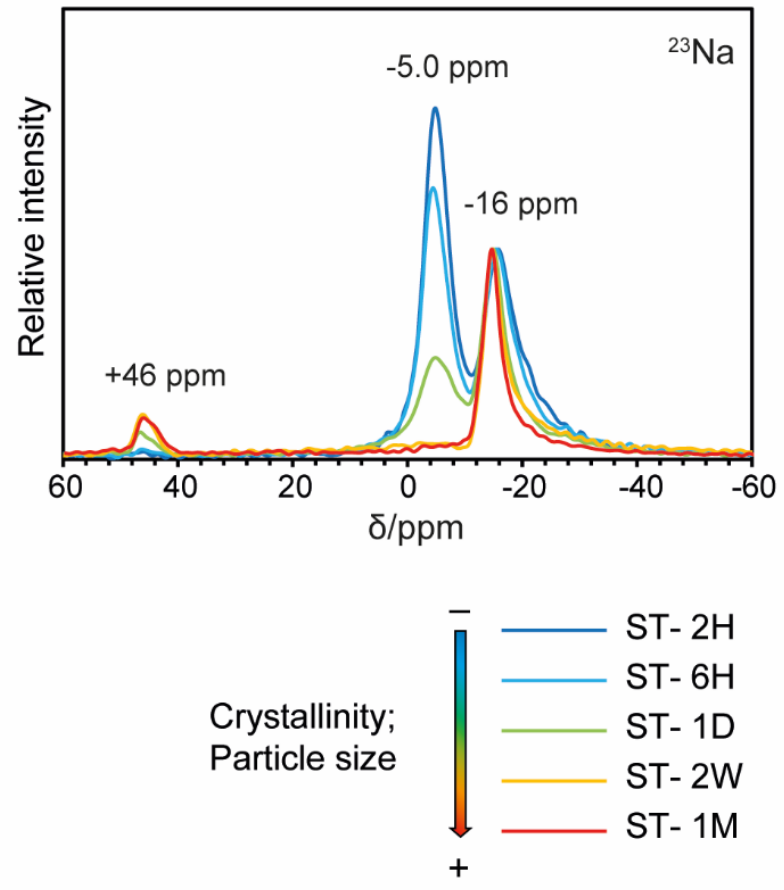

Figure 2. (a) ${ }^{1} \mathrm{H}$, (b) ${ }^{29} \mathrm{Si}$ and (c) ${ }^{23} \mathrm{Na}$ DP-MAS NMR spectra obtained for the series of synthetic talc samples. 
All of the samples present two major peaks at around $+4.0 \mathrm{ppm}$ and $+0.4 \mathrm{ppm}$. According to Dumas et al, $2013,{ }^{10}$ these peaks correspond respectively to adsorbed water and structural hydrogens $\left(\mathrm{Mg}_{3} \mathrm{OH}^{*}\right)$, meaning that $\mathrm{H}$ species that are attached to the $\mathrm{Mg}$ octahedra, and that are pointing up and down in the talc structure, inside the hexagonal rings of Si tetrahedra (Figure $3)$.

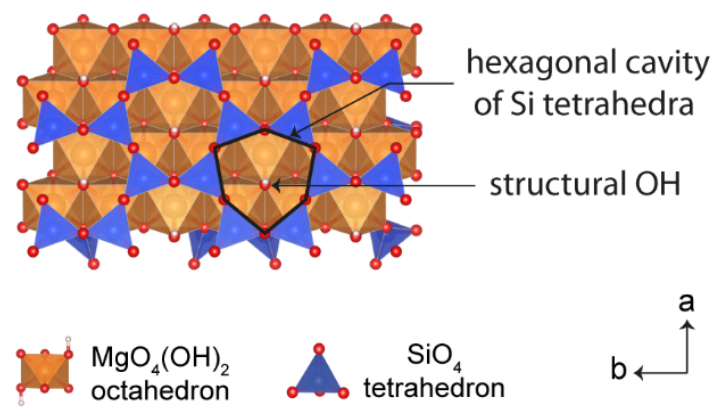

Figure 3. Hexagonal rings of Si tetrahedra with structural $\mathrm{OH}$ groups in the centers.

The decrease of the Full Width at Half Maximum (FWHM) of the "structural OH" species when the duration of synthesis increases testifies an increase of crystallinity of the samples as observed in the previous XRD results. Moreover, the Dumas e al. ${ }^{10}$ showed the presence of another peak at $+1.8 \mathrm{ppm}$ that they logically attributed to silanols groups located at the edges of the particles $\left(\mathrm{SiOH}^{*}\right)$ as its area decreases when the particle size increases, and because the $\mathrm{SiOH}$ groups are reported to resonate at these frequencies. ${ }^{33,34}$ However, in our study, this peak does not appear systematically even for very small particles where the amount of silanols edges is important (Figure 2a). To reconsider this attribution, the two synthesis protocols of both studies were meticulously compared. The only difference came from the number of washing steps (aiming at eliminating the excess of sodium acetate salts used in the synthesis) which was more important in our case (4 washings instead of 3). The ${ }^{1} \mathrm{H}$ DP-MAS NMR spectrum of sodium acetate was therefore recorded and showed a signal at $+1.7 \mathrm{ppm}$ located approximately at the same chemical shift than silanols (Figure S2). This observation led us to believe that the 
signal observed at $+1.8 \mathrm{ppm}$ in the talc nanoparticles was related to the presence of residual acetate species.

In order to test this hypothesis, a 2D $\left\{{ }^{1} \mathrm{H}\right\}-{ }^{13} \mathrm{C}$ HETCOR spectrum was recorded on the sample ST-AcONa (Figure S3) which contains a higher amount of sodium acetate salts than the other samples due to a reduced number of washing steps. The results evidence a correlation zone between the peak at $+1.8 \mathrm{ppm}$ in ${ }^{1} \mathrm{H}$ with the peak at $+24 \mathrm{ppm}$ in the ${ }^{13} \mathrm{C}$ NMR spectrum (the ${ }^{1} \mathrm{H}$ and ${ }^{13} \mathrm{C}$ DP-MAS NMR spectra were added to facilitate the reading). Since the sodium acetate salt is the only carbon-based compound used in the synthesis protocol, we can affirm that the peak at +1.8 ppm has a major contribution from sodium acetate residues, and not only from $\mathrm{SiOH}$. The observed correlation is indeed induced by the $\mathrm{CH}_{3}$ groups of sodium acetates, whose chemical shifts correspond to the expected values given by simulation softwares. This result evidences the importance of thoroughly washing the samples at the end of each synthesis to avoid traces of sodium acetate.

Other observations can be done on the ${ }^{1} \mathrm{H}$ NMR spectrum of the series of nano-sized talc samples (Figure 2a). Firstly, two shoulders located at around $+0.2 \mathrm{ppm}$ and $-0.2 \mathrm{ppm}$ appear in the spectra (Figure S4). These had never been observed by the past because of the different analysis conditions that were used (the rotor was spun at $8 \mathrm{kHz}$ instead of $45 \mathrm{kHz}$ like in this work, generating a broadening of the ${ }^{1} \mathrm{H}$ NMR peaks). These shoulders seem to be related to the crystallinity since they have almost disappeared for ST-1M. However, a more precise interpretation cannot be done at this stage. Finally, two small peaks located at $+0.8 \mathrm{ppm}$ and $0.6 \mathrm{ppm}$ are also visible in the spectra. These experimental spectra remained unchanged for different recycle delays (5 and $15 \mathrm{~s}$ ) and magnetic field intensities; therefore, we can exclude the choice of recycle delay as the cause either of the absence of highly deshielded strong hydrogen bond donor hydroxyls, or of the undetected silanols. 
We conclude that strong hydrogen donor hydroxyls (or strong Brönsted acids) do not exist or are in negligible amounts in nanotalcs prepared in our conditions

The DP-MAS NMR ${ }^{29}$ Si spectra obtained on the same series are presented in Figure $2 b$. The nano-sized talc samples evidence three types of Si environments located at around $-98 \mathrm{ppm}$, $-95 \mathrm{ppm}$ and $-86 \mathrm{ppm}$. The major peak at $-98 \mathrm{ppm}$ is described by several authors, ${ }^{18,35-38}$ and assigned to $\mathrm{Q}^{3}$ species, that is $\mathrm{Si}$ atoms linked to three OSi within the tetrahedral sheet. In the series of synthetic talc, the FWHM of this signal diminishes when the duration of synthesis in the samples increases, confirming the progressive enhancement of crystallinity. The two other resonances at $-95 \mathrm{ppm}$ and $-86 \mathrm{ppm}$ were considered by Dumas et al., $2016^{11}$ and assigned respectively to $\mathrm{Q}^{2}$ species ( $\mathrm{Si}$ atoms linked to two $\mathrm{OSi}$ and one $\mathrm{OH}$ group) and talc precursor entities. As shown in the following, these interpretations will be reconsidered.

${ }^{23} \mathrm{Na}$ DP-MAS NMR analyses were performed because of the presence of sodium acetate traces in the nano-sized samples (as evidenced by ${ }^{1} \mathrm{H}$ NMR). Surprisingly, up to 3 environments of $\mathrm{Na}$ are observed: One at $+46 \mathrm{ppm}$, one at $-5 \mathrm{ppm}$ and another one at $-16 \mathrm{ppm}$ (Figure 2c). The signal at $+46 \mathrm{ppm}$ appears only for synthesis duration of one day or more while the one at $-5 \mathrm{ppm}$ decreases when the synthesis time increases. The signal at $-16 \mathrm{ppm}$ remains stable whatever the duration of synthesis. These three signals can be compared to the ones observed by Cattaneo et al, 2011 on synthetic fluoromica. ${ }^{39}$ The latter presents a structure very similar to synthetic talc as it is composed of one sheet of $\mathrm{Mg}$ octahedra surrounded by two sheets of Si tetrahedra. The difference comes only from limited partial substitution of Si by Al in the tetrahedral sheets, the presence of fluorine atoms in replacement of the structural $\mathrm{OH}$ groups, and from a net negative charge linked to magnesium vacancies and compensated by $\mathrm{Na}^{+}$ions in the interlayer space. The authors report an approximate composition of $\mathrm{Na}_{0.66} \mathrm{Mg}_{2.68}\left(\mathrm{Si}_{3.98} \mathrm{Al}_{0.02}\right) \mathrm{O}_{10.02} \mathrm{~F}_{1.96}$ from the chemical analyses of their fluoromica samples, to be compared with the theoretical stoichiometry for talc, $\mathrm{Si}_{4} \mathrm{Mg}_{3} \mathrm{O}_{10}(\mathrm{OH})_{2}$. Like in the case of 
synthetic talc, the authors observe three signals at $+37 \mathrm{ppm},-2.3 \mathrm{ppm}$ and $-19.8 \mathrm{ppm}$, respectively attributed to nonexchangeable $\mathrm{Na}^{+}$ions (meaning octahedral $\mathrm{Na}$ ), hydrated $\mathrm{Na}^{+}$ ions and nonhydrated $\mathrm{Na}^{+}$ions. From the integration of the ${ }^{23} \mathrm{Na}$ MAS NMR spectrum, Cattaneo et al. ${ }^{39}$ conclude that $80 \%$ of sodium ions are in the interlayer space, and $20 \%$, i.e., 0.13 sodium ions per unit cell, are occupying $\mathrm{Mg}$ sites within the layers. The missing 0.19 sites to complete the stoichiometry to $3 \mathrm{Mg}$ per unit cell must be described as $\mathrm{Mg}$ vacancy octahedral environment. The very similar structure of both materials, as well as the close positions of the NMR signals led us to consider an analogous assignment for the signals at $+46 \mathrm{ppm},-5 \mathrm{ppm}$ and -16 ppm observed here. Thus, the presence of exchangeable species in synthetic talc could come both from the substitution of $\mathrm{Mg}^{2+}$ ions by $\mathrm{Na}^{+}$ions and from octahedral vacancies, causing a deficit of charge in the TOT layer. This deficit would be compensated by the exchangeable species in the interlayer space or by adsorbed species on external basal planes. It has yet to be noticed that the percentage of $\mathrm{Na}$ in the samples of the present series remains extremely low (about 1 wt.\% determined by microprobe analysis). Cation exchange capacity (CEC) experiments were attempted but appeared inconclusive.

Two-Dimensional MAS NMR Experiments. 2D correlations techniques were used to evaluate the consistency of the interpretations made from the DP-MAS NMR experiments. The HETCOR and D-HMQC experiments correspond to heteronuclear correlations that probe the spatial proximity existing between different couples of species through dipolar coupling. The difference between the two is that the HETCOR concerns two spins $1 / 2\left({ }^{1} \mathrm{H},{ }^{13} \mathrm{C},{ }^{29} \mathrm{Si}\right)$ while the D-HMQC concerns a spin $1 / 2\left({ }^{1} \mathrm{H},{ }^{13} \mathrm{C},{ }^{29} \mathrm{Si}\right)$ and a quadrupolar spin $\left({ }^{23} \mathrm{Na}\right)$. To facilitate the reading of the results, the DP-MAS NMR spectra in each experiment were added.

The 2D $\left\{{ }^{1} \mathrm{H}\right\}-{ }^{29} \mathrm{Si}$ HETCOR spectrum recorded on ST-6H is presented on Figure 4a. Three groups of species cross-correlate: A first one between the species resonating at $-98 \mathrm{ppm}$ in the ${ }^{29} \mathrm{Si}$ dimension and $+0.4 \mathrm{ppm}$ in the ${ }^{1} \mathrm{H}$ dimension, and two other ones between the species 
resonating at $-95 \mathrm{ppm}$ in the ${ }^{29} \mathrm{Si}$ dimension and $+0.2 \mathrm{ppm}$ and $-0.2 \mathrm{ppm}$ in the ${ }^{1} \mathrm{H}$ dimension. The first correlation is consistent with the previous NMR assignments since the $\mathrm{Q}^{3}$-type $\mathrm{Si}$ atoms $(-98 \mathrm{ppm})$ are spatially close to the structural $\mathrm{OH}$ groups in the talc structure $(+0.4 \mathrm{ppm})$. The two other correlations are however more enigmatic since the peak at $-95 \mathrm{ppm}$ (interpreted by Dumas and co-workers ${ }^{10,11}$ as $\mathrm{Q}^{2}$-type species, meaning $\mathrm{Si}^{*} \mathrm{OH}$ groups) does not fit with the expected chemical shift of $\mathrm{H}$ atoms in the same configuration ( $\mathrm{SiOH}^{*}$ groups). Indeed, according to the literature ${ }^{33,34}$ the latter should arise at around $+1.8 \mathrm{ppm}$ whereas here the correlation signal appears at $+0.2 \mathrm{ppm}$ and $-0.2 \mathrm{ppm}$. These positions are very far from the theoretical range of silanols. The assignation made by Dumas et al, 2013, 2016 ${ }^{10,11}$ has to be consequently reconsidered. 


Figure 4. Two-dimensional (a) $\left\{{ }^{1} \mathrm{H}\right\}-{ }^{29} \mathrm{Si} \mathrm{HETCOR}$ spectrum of ST-6H; (b) $\left\{{ }^{29} \mathrm{Si}\right\}-{ }^{23} \mathrm{Na} \mathrm{D}$ HMQC spectrum of ST-6H; (c) $\left\{{ }^{1} \mathrm{H}\right\}-{ }^{23} \mathrm{Na}$ D-HMQC spectrum of ST-1D.

The 2D $\left\{{ }^{29} \mathrm{Si}\right\}-{ }^{23} \mathrm{Na} \mathrm{D}-\mathrm{HMQC}$ MAS NMR spectrum recorded on ST-6H is presented on Figure 4b. It evidences a correlation between the species resonating at $-95 \mathrm{ppm}$ in ${ }^{29} \mathrm{Si}$ and the ones resonating at $-16 \mathrm{ppm}$ in ${ }^{23} \mathrm{Na}$. The peak at $-16 \mathrm{ppm}$ was, according to Cattaneo et al. ${ }^{39}$, attributed to nonhydrated exchangeable $\mathrm{Na}^{+}$ions located in the interlayer space. These species are thus close to the $\mathrm{Si}$ atoms resonating at $-95 \mathrm{ppm}$. Although this observation brings new information on the nature of these Si environments, it is still not sufficient to know their exact location.

Finally, a 2D $\left\{{ }^{1} \mathrm{H}\right\}-{ }^{23} \mathrm{Na}$ D-HMQC MAS NMR spectrum was recorded on ST-1D (Figure 4c). This sample was selected because it contains the three types of $\mathrm{Na}$ environments possibly present in the talc structure (see Figure 2c). The results evidence two correlation zones: A first one between the species resonating at $-0.2 \mathrm{ppm}$ in the ${ }^{1} \mathrm{H}$ dimension and $+46 \mathrm{ppm}$ in the ${ }^{23} \mathrm{Na}$ dimension, and another one between the species resonating at $+0.2 \mathrm{ppm}$ in the ${ }^{1} \mathrm{H}$ dimension and $-16 \mathrm{ppm}$ in the ${ }^{23} \mathrm{Na}$ dimension. The $\mathrm{Na}$ species resonating at $-5.0 \mathrm{ppm}$ do not correlate with any $\mathrm{H}$ species. At this stage, these observations are difficult to interpret because of the lack of knowledge concerning the origin of the $\mathrm{H}$ environments.

This NMR study confirms the assignment of the main signals identified on large talc particles $\left(-98 \mathrm{ppm}\right.$ in ${ }^{29} \mathrm{Si}$ and $+0.4 \mathrm{ppm}$ in $\left.{ }^{1} \mathrm{H}\right)$ due to $\mathrm{Q}^{3}$-type $\mathrm{Si}$ atoms and to structural $\mathrm{OH}$ groups. Nevertheless, the synthetic talc samples show clearly specific signals in each NMR spectrum (-86 and $-95 \mathrm{ppm}$ in ${ }^{29} \mathrm{Si} ;-0.6 \mathrm{ppm},+0.2 \mathrm{ppm},-0.2 \mathrm{ppm}$ and $+0.8 \mathrm{ppm}$ in ${ }^{1} \mathrm{H} ;-5.0$, 16 and $+46 \mathrm{ppm}$ in ${ }^{23} \mathrm{Na}$ ) because of their small particle size and small content in $\mathrm{Na}^{+}$ions that can be hardly assigned on the sole basis of NMR results. DFT calculations were thus performed to model some likely structural configurations and their corresponding NMR signature. 


\section{COMPUTATIONAL RESULTS}

Choice of Atomistic Models. The strategy adopted consists in the comparison of experimental with predicted NMR chemical shifts for the nuclei of interest in well-defined model situations: Bulk defect free crystals of talc and fluoromica, modelled by reference experimental unit-cells relaxed to a minimal total energy with respect to the DFT approximations adopted, bulk unitcells including substitutional defects at octahedral sites and the associated charge compensations by $\mathrm{Na}^{+}$ions in the Interlayer Space (IS) between TOT layers, and surface models. Fluoromica models were considered in view of the former detailed experimental study by Cattaneo et al. ${ }^{39}$ and their inspiring but incomplete assignations of the ${ }^{23} \mathrm{Na}$ signals observed for these talc derived materials.

As surface models, we have considered talc "edge" planes obtained by cleavage of the bulk along $(\mathrm{h}, \mathrm{k}, 0)$ planes, and the $\{001\}$ basal plane: We report elsewhere ${ }^{40}$ the results of a theoretical surface thermodynamic study showing that talc equilibrium morphology at $600 \mathrm{~K}$ in presence of liquid water expresses exclusively $\{130\},\{100\}$ and the major $\{001\}$ basal plane. The fully hydrated $\{130\}$ and $\{100\}$ surfaces terminations involve as expected $\mathrm{Q}^{2} \mathrm{Si}$ atoms and silanols (\#Si-OH) resulting from the dissociative chemisorption of $\mathrm{H}_{2} \mathrm{O}$, as well as five-fold coordinated $\mathrm{Mg}^{++}$ions to adjacent structural $\mathrm{O}^{=}$and $\mathrm{OH}^{-}$anions, plus a molecularly chemisorbed $\mathrm{H}_{2} \mathrm{O}$ molecule completing each inner sphere surface complex. The $\{001\}$ defect free basal surface does not chemisorb water, as expected from the well-known hydrophobicity of natural (micron-sized) talc, and involves only unperturbed $\mathrm{Q}^{3}$ Si tetrahedral environments.

Moreover, we designed insightful yet computationally tractable minimal models including water/basal planes interfaces with or without charge compensating substitutional defects. These models consist of $1 \times 1 \times 2$ talc supercells, i.e. involving 4 TOT layers initially, 
from which 1 TOT layer has been removed and the void filled by 20 water molecules (Bulk water), so as to match the density of ordinary liquid water. The initial geometry and configuration of this model nanoliquid sample of liquid water was obtained from the DFT optimization of a cubic cell of side $1.5 \mathrm{~nm}$ previously filled to the required density at ambient temperature by a Monte-Carlo algorithm, as described in the computational details section.

Defect Free Talc. Figure 5 displays a picture of the reference talc unit-cell after optimization of atomic positions keeping unit-cell parameters to their experimental values.

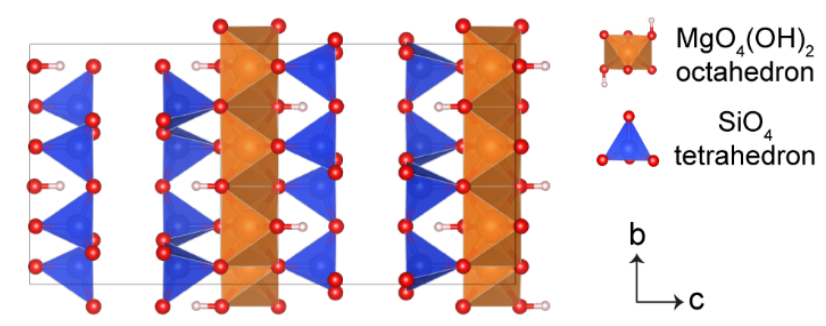

Figure 5. Unit-cell of the reference talc structure.

The predicted chemical shifts for this model are reported in Table 2, line 7. An excellent agreement is obtained with published values for natural talc ${ }^{37},-98 \mathrm{ppm}$ and $+0.4 \mathrm{ppm}$ for $\delta{ }^{29} \mathrm{Si}$ and $\delta{ }^{1} \mathrm{H}$ and our own experimental results. 


\section{Table 2. Predicted Chemical Shifts in ppm for Defective Bulk Talc and Fluoromica}

\section{Models $^{a}$}

\begin{tabular}{|c|c|c|c|c|c|c|c|c|c|c|c|c|}
\hline \multirow[b]{3}{*}{$\mathrm{N}^{\circ}$} & \multirow[b]{2}{*}{$\underset{1}{\operatorname{minera}}$} & \multirow[b]{2}{*}{$\begin{array}{c}\text { defec } \\
t\end{array}$} & \multicolumn{6}{|c|}{ defective TOT layer } & \multicolumn{4}{|c|}{ normal TOT layer } \\
\hline & & & $\begin{array}{l}{ }^{23} \mathrm{Na} \\
\text { Subs }\end{array}$ & $\begin{array}{l}{ }^{23} \mathrm{Na} \\
\text { or }{ }^{1} \mathrm{H} \\
\text { Comp }\end{array}$ & ${ }^{29} \mathrm{Si}$ & ${ }^{1} \mathrm{H}$ & ${ }^{25} \mathrm{Mg}$ & ${ }^{19} \mathrm{~F}$ & ${ }^{29} \mathrm{Si}$ & ${ }^{1} \mathrm{H}$ & ${ }^{25} \mathrm{Mg}$ & ${ }^{19} \mathrm{~F}$ \\
\hline & 1 & 2 & 3 & 4 & 5 & 6 & 7 & 8 & 9 & 10 & 11 & 12 \\
\hline 1 & & BD1- & $\begin{array}{l}+41.7 \\
+0.00\end{array}$ & $\begin{array}{c}-4.8 \\
\pm 0.00\end{array}$ & $\begin{array}{l}-95.8 \\
+1.81\end{array}$ & $\begin{array}{l}-0.67 \\
\pm 0.47\end{array}$ & $\begin{array}{l}+20.4 \\
+0.50\end{array}$ & - & $\begin{array}{l}-98.5 \\
+1.50\end{array}$ & $\begin{array}{l}+0.36 \\
+0.29\end{array}$ & $\begin{array}{l}+21.1 \\
+0.09\end{array}$ & - \\
\hline 2 & & $\begin{array}{l}\text { BD1- } \\
\text { II }\end{array}$ & $\begin{array}{l}+41.4 \\
\pm 0.00\end{array}$ & $\begin{array}{c}-5.4 \\
\pm 0.00\end{array}$ & $\begin{array}{l}-96.1 \\
\pm 1.94\end{array}$ & $\begin{array}{l}-0.63 \\
\pm 0.48\end{array}$ & $\begin{array}{l}+20.3 \\
\pm 0.44\end{array}$ & - & $\begin{array}{l}-98.4 \\
\pm 1.62\end{array}$ & $\begin{array}{l}+0.35 \\
\pm 0.31\end{array}$ & $\begin{array}{l}+21.1 \\
\pm 0.08\end{array}$ & - \\
\hline 3 & & $\begin{array}{l}\text { BD2- } \\
\text { I }\end{array}$ & $\begin{array}{c}+42.9 \\
\pm 0.0\end{array}$ & $\begin{array}{l}+5.3^{b} \\
\pm 0.84\end{array}$ & $\begin{array}{l}-96.8 \\
\pm 1.04\end{array}$ & $\begin{array}{l}+0.09 \\
\pm 0.27\end{array}$ & $\begin{array}{l}+23.7 \\
\pm 2.00\end{array}$ & - & $\begin{array}{l}-97.2 \\
\pm 0.48\end{array}$ & $\begin{array}{l}+0.38 \\
\pm 0.07\end{array}$ & $\begin{array}{l}+22.5 \\
\pm 0.10\end{array}$ & - \\
\hline 4 & talc & $\begin{array}{l}\text { BD3- } \\
\text { I }\end{array}$ & - & $\begin{array}{l}-0.76 \\
\pm 0.31\end{array}$ & $\begin{array}{l}-94.0 \\
\pm 0.24\end{array}$ & $\begin{array}{l}-0.34 \\
\pm 0.62\end{array}$ & $\begin{array}{l}+19.1 \\
\pm 0.90\end{array}$ & - & $\begin{array}{l}-98.5 \\
\pm 1.08\end{array}$ & $\begin{array}{l}+0.42 \\
\pm 0.03\end{array}$ & $\begin{array}{l}+21.1 \\
\pm 0.12\end{array}$ & - \\
\hline 5 & & $\begin{array}{c}\text { BD3- } \\
\text { II }\end{array}$ & - & $\begin{array}{l}-0.98 \\
\pm 0.03\end{array}$ & $\begin{array}{l}-94.0 \\
\pm 0.16\end{array}$ & $\begin{array}{l}-0.13 \\
\pm 0.65\end{array}$ & $\begin{array}{l}+19.3 \\
\pm 0.34\end{array}$ & - & $\begin{array}{l}-98.5 \\
\pm 1.08\end{array}$ & $\begin{array}{l}+0.41 \\
\pm 0.07\end{array}$ & $\begin{array}{l}+21.0 \\
\pm 0.08\end{array}$ & - \\
\hline 6 & & BD4 & - & $\begin{array}{l}+3.90 \\
\pm 0.00\end{array}$ & $\begin{array}{l}-95.1 \\
\pm 0.40^{\mathrm{d}}\end{array}$ & $\begin{array}{l}-0.1^{\mathrm{e}} \\
\pm 0.25\end{array}$ & $\begin{array}{l}+24.8^{\mathrm{f}} \\
\pm 0.28\end{array}$ & - & $\begin{array}{l}-98.4 \\
\pm 1.02\end{array}$ & $\begin{array}{l}+0.36 \\
\pm 0.17\end{array}$ & $\begin{array}{l}+21.0 \\
\pm 0.10\end{array}$ & - \\
\hline 7 & & No & - & - & - & - & - & - & $\begin{array}{l}-98.0 \\
\pm 0.01\end{array}$ & $\begin{array}{l}+0.40 \\
\pm 0.00\end{array}$ & $\begin{array}{l}+21.1 \\
\pm 0.17\end{array}$ & - \\
\hline 8 & & $\begin{array}{l}\text { BD1- } \\
\text { I }\end{array}$ & $\begin{array}{c}+33.9 \\
\pm 0.0\end{array}$ & $\begin{array}{l}+1.28 \\
\pm 0.0\end{array}$ & $\begin{array}{l}-96.4 \\
\pm 1.70\end{array}$ & - & $\begin{array}{l}+20.2 \\
\pm 0.34\end{array}$ & $\begin{array}{l}-176.0 \\
\pm 2.24^{\mathrm{c}}\end{array}$ & $\begin{array}{l}-99.5 \\
\pm 1.80\end{array}$ & - & $\begin{array}{l}+21.4 \\
\pm 0.47\end{array}$ & $\begin{array}{l}-174.5 \\
\pm 0.08\end{array}$ \\
\hline 9 & & $\begin{array}{l}\text { BD1- } \\
\text { II }\end{array}$ & $\begin{array}{c}+34.2 \\
\pm 0.0\end{array}$ & $\begin{array}{l}-0.88 \\
\pm 0.0\end{array}$ & $\begin{array}{l}-96.6 \\
\pm 1.89\end{array}$ & - & $\begin{array}{l}+19.8 \\
\pm 0.74\end{array}$ & $\begin{array}{r}-177.3 \\
\pm 1.84\end{array}$ & $\begin{array}{l}-99.9 \\
\pm 1.80\end{array}$ & - & $\begin{array}{l}+19.9 \\
\pm 0.16\end{array}$ & $\begin{array}{l}-175.2 \\
\pm 0.07\end{array}$ \\
\hline 10 & $\begin{array}{l}\text { fluoro- } \\
\text { mica }\end{array}$ & $\begin{array}{l}\text { BD3- } \\
\text { I }\end{array}$ & - & $\begin{array}{c}+16.1 \\
\pm 3.9\end{array}$ & $\begin{array}{l}-97.4 \\
\pm 1.14\end{array}$ & _ & $\begin{array}{l}+13.9 \\
\pm 1.26\end{array}$ & $\begin{array}{l}-171.5 \\
\pm 3.09\end{array}$ & $\begin{array}{l}-99.0 \\
\pm 1.03\end{array}$ & _ & $\begin{array}{l}+16.4 \\
\pm 0.25\end{array}$ & $\begin{array}{c}-174.8 \\
\pm 0.20\end{array}$ \\
\hline 11 & & $\begin{array}{l}\text { BD3- } \\
\text { II }\end{array}$ & - & $\begin{array}{l}+1.1 \\
\pm 0.00\end{array}$ & $\begin{array}{l}-93.3 \\
\pm 0.29\end{array}$ & - & $\begin{array}{l}+16.4 \\
\pm 0.66\end{array}$ & $\begin{array}{l}-175.8 \\
\pm 0.03\end{array}$ & $\begin{array}{l}-99.3 \\
\pm 1.10\end{array}$ & - & $\begin{array}{l}+20.4 \\
\pm 0.20\end{array}$ & $\begin{array}{l}-174.6 \\
\pm 0.08\end{array}$ \\
\hline 12 & & No & - & - & - & - & - & - & $\begin{array}{l}-99.4 \\
\pm 0.01\end{array}$ & - & $\begin{array}{l}+20.1 \\
\pm 0.11\end{array}$ & $\begin{array}{l}175.3 \\
\pm 0.00\end{array}$ \\
\hline
\end{tabular}

${ }^{a}$ Each unit-cell includes 2 TOT layers, and one of them is perturbed by the substitutional defect.

Values reported are averages, and average deviations for the various nuclei and situations. ${ }^{\mathrm{b}}$ The charge is compensated by addition of a proton to a structural $\mathrm{OH}$ group resulting in a structural water molecule with $\delta{ }^{1} \mathrm{H}=+4.47$ and $+6.15 \mathrm{ppm} .{ }^{c} \mathrm{~F}$ opposed to $\mathrm{Na}^{+}$substituent has $\delta{ }^{19} \mathrm{~F}=-$ $180.4 \mathrm{ppm} .{ }^{\mathrm{d}}$ Value for Si on the Na side of the defective TOT layer, while same $\delta{ }^{29} \mathrm{Si}$ as normal on the other side. ${ }^{\mathrm{e}} \delta^{21} \mathrm{H}=-0.47 \mathrm{ppm}$ on the Na side of the defective TOT Layer. ${ }^{\mathrm{f}}$ Value for $\mathrm{Mg}$ nearest to $\mathrm{Na}$ in the defective TOT layer, while same $\delta{ }^{25} \mathrm{Mg}$ as normal for farthest. 


\section{Influence of Defects: $\mathrm{Mg}^{2+}$ Substitutions by $\mathrm{Na}^{+}$or Vacancies, Compensated by "Exchangeable" $\mathrm{Na}^{+}$Cations in Talc and Fluoromica, and $\mathrm{OH}$ Substitution by $\mathrm{ONa}$ in}

Talc.

In order to complete as far as possible our sampling of possible environments for $\mathrm{Na}$ in synthetic talc and fluoromica, we have considered $\mathrm{Mg}^{2+}$ substitution by $\mathrm{Na}^{+}$, with charge compensation by another $\mathrm{Na}^{+}(\mathrm{BD} 1)$ or one $\mathrm{H}^{+}$(BD2) in IS, and a vacant $\mathrm{Mg}^{2+}$ site, with charge compensation by 2 vicinal $\mathrm{Na}^{+}$in IS (BD3). Since as pointed out by Cattaneo et al. ${ }^{39}$ there are two unequivalent octahedral $\mathrm{Mg}^{2+}$ sites in talc and fluoromica, $\mathrm{Mg}(\mathrm{I})$ and $\mathrm{Mg}(\mathrm{II})$ according to the cis or trans positions of structural $\mathrm{OH}^{-}$or $\mathrm{F}^{-}$ions at summits of the corresponding octahedra, we have also compared defects for these configurations to some extent (BDi-I or BDi-II). In order to model fluoromica we simply substituted all structural $\mathrm{OH}^{-}$anions by $\mathrm{F}^{-}$in the reference talc unit-cell, then optimized cell parameters and atomic positions. Additionally, we have considered substitutions of structural protons by $\mathrm{Na}^{+}$in talc (BD4). The results are summarized in Table 2. From the inspection of Table 2 we can conclude that:

(1) In general, our relatively simple 2 TOT layers model unit-cells are sufficient to distinguish clearly defective from normal layers. This was expected since in these layered materials, no strong chemical bonds couple successive TOT layers, which interact only through long range dispersive forces, unless charged defects are present. For both talc and fluoromica models, the computed NMR shifts for normal (non-defective) TOT layers differ hardly from those obtained for ideal crystals (columns 9 to 12 in Table 2, lines 1-6 referred to line 7, lines 8-11 referred to line 12). We notice however that defects affecting the adjacent TOT induce significant broadenings of $\delta{ }^{29} \mathrm{Si}$ and $\delta{ }^{1} \mathrm{H}$ ranges, while averages remain comparable to ideal references. For instance, the average deviation of $\pm 1.6 \mathrm{ppm}$ in the non-defective layer for $\mathrm{Mg}(\mathrm{II})$ substitution by $\mathrm{Na}^{+}$in talc (line 2, column 9 of Table 2) reflects the fact that the computed $\delta$ ${ }^{29} \mathrm{Si}$ fluctuates between -100.2 and $-95.9 \mathrm{ppm}$ for sites in the normal layer closest to the 
compensating $\mathrm{Na}^{+}$ion located in IS (see Figure 6, ions Si27 and Si31 in the ideal and normal layer positions respectively). Hence, as expected, rather long-range electrostatic effects do affect shielding tensors through charge transfers.

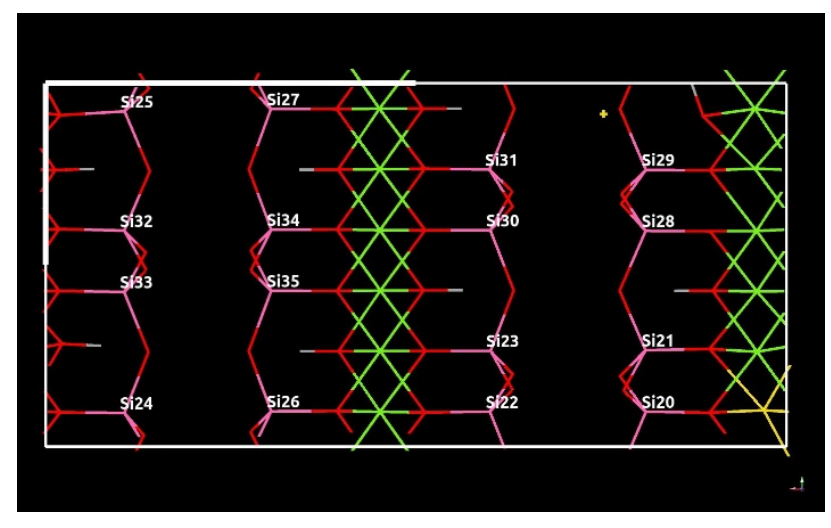

Figure 6. Unit-cell of the optimized $\mathrm{H}_{8} \mathrm{Na}_{2} \mathrm{O}_{48} \mathrm{Mg}_{11} \mathrm{Si}_{16}$ talc structure viewed along the $\vec{a}$ axis: Color code: Na yellow, Mg green, $\mathrm{H}$ grey, O red, Si pink. The defective TOT layer (right and left part of the periodic box) has one $\mathrm{Mg}$ (II) substituted by one $\mathrm{Na}^{+}$. The second $\mathrm{Na}^{+}$is stabilized in IS above the center of the hexagonal ring delineated by Si28, Si29, Si21, Si20 and their counterparts by symmetry.

(2) The best model for the experimental ${ }^{23} \mathrm{Na}$ signal we report for nanotalc at $+46 \mathrm{ppm}$ corresponds to the substitution of one $\mathrm{Mg}^{2+}$ by one $\mathrm{Na}^{+}$in an octahedral site (lines 1,2 and 3 of Table 2). The fluoromica models however lead to values slightly lower (lines 8 and 9 of Table 2) than reported experimentally by Cattaneo et al. ${ }^{39}\left(\delta{ }^{23} \mathrm{Na}=37 \mathrm{ppm}\right)$ for "nonexchangeable" Na. On the basis of modelling of their experimental ${ }^{23} \mathrm{Na}\left\{{ }^{19} \mathrm{~F}\right\}$ REDOR curves, these authors claim that substitution at $\mathrm{Mg}(\mathrm{I})$ cis sites is preferred over that at $\mathrm{Mg}(\mathrm{II})$ trans sites. However, in our simulations, we find that the latter is slightly favored at least in terms of total energy (by 0.03 and $0.34 \mathrm{eV} /$ unit-cell for substituted talcs and fluoromicas respectively). Notice that for talc, charge compensation by $\mathrm{H}^{+}$, i.e. replacing a structural hydroxyl group by a "structural" 
water molecule cannot be ruled out: in such case, the corresponding ${ }^{1} \mathrm{H}$ signal will not be distinguishable from that of residual adsorbed water.

(3) The substitution of one $\mathrm{Mg}^{2+}$ by one $\mathrm{Na}^{+}$in an octahedral site requires a charge compensation by a $\mathrm{Na}^{+}$or $\mathrm{H}^{+}$in the adjacent IS. Following chemical common sense, in our models we position these cations initially slightly above the center of one of the nearest hexagonal rings formed by the defective TOT topmost layer of $\mathrm{O}^{-}$anions and allow ions relaxation. In this way, we do reproduce correctly the experimental signal found at $-5 \mathrm{ppm}$ on nanotalc (lines 1 and 2 of Table 2). Besides, our fluoromica models predict signals slightly less negative than found by Cattaneo et al. ${ }^{39}$ for "exchangeable" $\mathrm{Na}(\mathrm{I})$ ions $\left(\delta^{23} \mathrm{Na}=-2.3 \mathrm{ppm}\right)$. The best agreement is obtained for $\mathrm{Mg}(\mathrm{II})$ substitution (line 9 of Table 2), with $\delta^{23} \mathrm{Na}=-0.88 \mathrm{ppm}$ for the compensation cation. Note however that in our case, this value is obtained for an anhydrous $\mathrm{Na}^{+}$cation whereas the authors report a hydrated $\mathrm{Na}^{+}$cation.

(4) Defective TOT layers show in general significant perturbations of the averages and ranges of NMR shifts for ${ }^{29} \mathrm{Si},{ }^{1} \mathrm{H},{ }^{25} \mathrm{Mg}$ and ${ }^{19} \mathrm{~F}$ (columns 5 to 8 in Table 2, referred to lines 7 and 12). Shifts for $\mathrm{Q}^{3} \mathrm{Si}$ increase by circa $3 \mathrm{ppm}$ as experimentally found, but for ${ }^{1} \mathrm{H}$ in talc they decrease by circa $1.0 \mathrm{ppm}$ instead of circa $0.2 \mathrm{ppm}$ in experiments. Combined with the fact that none of these models reproduces the $\delta^{23} \mathrm{Na}=-16 \mathrm{ppm}$ clearly correlated to $\delta{ }^{1} \mathrm{H}=+0.2 \mathrm{ppm}$ in talc (or $-19 \mathrm{ppm}$ for exchangeable $\mathrm{Na}(\mathrm{II})$ in fluoromica), this discrepancy suffices to rule out all of these bulk models, excepted possibly for $\mathrm{Na}^{+}$substitution to $\mathrm{Mg}^{2+}$ compensated by $\mathrm{H}^{+}$linked to a structural $\mathrm{OH}^{-}$group (line 3 in Table 2).

Examination of experimental trends in chemical shifts for the various nuclei considered here allow expecting for ${ }^{29} \mathrm{Si},{ }^{1} \mathrm{H},{ }^{23} \mathrm{Na}$ increased unshielding by strong Lewis bases as substituents in their coordination sphere at constant coordination number. For instance, $\delta{ }^{29} \mathrm{Si}$ : $\mathrm{TMS}=\mathrm{Si}\left(\mathrm{CH}_{3}\right)_{4}>\mathrm{Si}(\mathrm{OH})_{4}>\mathrm{Q}^{2}>\mathrm{Q}^{3}>\mathrm{Q}^{4}>\mathrm{SiF}_{4} ; \delta{ }^{1} \mathrm{H}: \mathrm{H}_{2} \mathrm{O}>\mathrm{TMS} ; \delta^{23} \mathrm{Na}^{\mathrm{Na}} \mathrm{Na}_{2} \mathrm{O}(+55 \mathrm{ppm})$ 
$>\mathrm{NaOH}(\mathrm{s})(+21 \mathrm{ppm})>\mathrm{NaCl}(\mathrm{s})(+7.9 \mathrm{ppm})>$ dehydrated $\mathrm{Na}-\mathrm{X}$ zeolite $(-2.7$ to $-21 \mathrm{ppm})>$ $\left(\mathrm{NaClO}_{4}(-20.4 \mathrm{ppm}){ }^{41,42}\right.$ Therefore, the defects induced variations of shifts for the affected TOT layers in our models reflect certain amount of delocalized charge transfer towards $\mathrm{O}^{2-}$ anions in response to the substitution of $\mathrm{Mg}^{2+}$ cations by less attractive $\mathrm{Na}^{+}$or $\mathrm{V}$ centers (vacancies). However, the observed signal at $\delta{ }^{23} \mathrm{Na}=-16 \mathrm{ppm}$ must correspond to a situation comparable to that found for a $\mathrm{Na}$ exchanged very acidic zeolite proton where the bridging oxygen $\mathrm{Si}^{4+}$ and $\mathrm{Al}^{3+}$ is a very weak base, although confinement effects might also play a role in zeolite cages. With such a guideline and since bulk models proved unable to offer such a situation, we chose to explore models representing interfaces between liquid water and defective TOT layers, as mentioned above.

\section{Interlayer Spaces and Interfaces of $\{001\}$ Basal Planes with Water Including Charge Compensated Substitutions at Octahedral Sites.}

Figure 7a-e shows optimized configurations of models involving two defective interfacial TOT layers and one normal "bulk" layer, with various defects. The notation W[Di]IS[N]IS[Dj]W stands for the periodic repeat along the $\vec{c}$ axis of: Bulk water, defective TOT layer with defect Di, Interlayer Space, Normal TOT layer, Interlayer Space, defective TOT layer with defect $\mathrm{Dj}$, and Bulk water. Defects are defined as:

(1) D1: one structural OH substituted by ONa, IS side

(2) D2: one structural $\mathrm{OH}$ substituted by $\mathrm{ONa}$, water side

(3) D3: one $\mathrm{Mg}(\mathrm{I})$ substituted by $\mathrm{Na}^{+}$, compensated by one $\mathrm{Na}^{+}$, IS side

(4) D4: one $\mathrm{Mg}(\mathrm{I})$ substituted by $\mathrm{Na}^{+}$, compensated by one $\mathrm{Na}^{+}$, water side

(5) D5: one $\mathrm{Mg}(\mathrm{I})$ substituted by a vacancy $\mathrm{V}$, compensated by one $\mathrm{Na}^{+}$IS side and one $\mathrm{Na}^{+}$ water side 
(6) D6: one $\mathrm{Mg}(\mathrm{I})$ substituted by a vacancy $\mathrm{V}$, compensated by one $\mathrm{H}^{+}$IS side and one $\mathrm{H}^{+}$water side

We have therefore: W[D1]IS[N]IS[D1]W shown on Figure 7a, W[D2]IS[N]IS[D2]W shown on Figure 7b, W[D4]IS[N]IS[D3]W shown on Figure 7c, W[D5]IS[N]IS[D5]W shown on Figure 7d, W[D6]IS[N]IS[D6]W shown on Figure 7e.
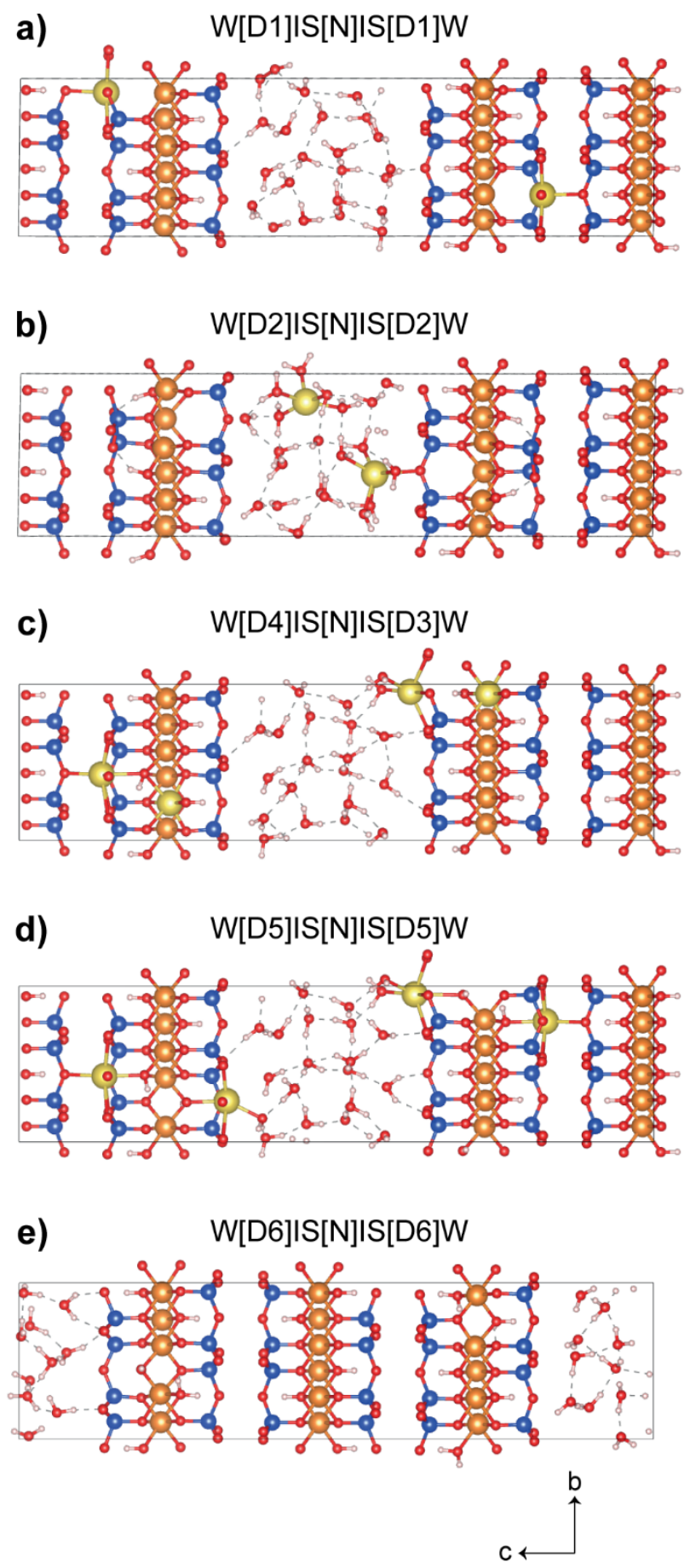
Figure 7. Optimized configurations of models involving a water layer, 2 defective interfacial TOT layers and one normal "bulk" layer, with various defects. Color code: Si blue, Mg orange, O red, $\mathrm{H}$ white, Na yellow.

Table 3 summarizes similarly to Table 2 the predicted chemical shifts obtained for these models.

Table 3. Predicted Chemical Shifts ${ }^{a}$ in $\mathbf{p p m}$ for Models Involving a Water Layer, 2 Defective Interfacial TOT Layers and One Normal "Bulk" Layer, with Various Defects (S: substituted; C: compensated)

\begin{tabular}{|c|c|c|c|c|c|c|}
\hline \multirow[b]{2}{*}{$\begin{array}{l}\text { TOT } \\
\text { layer }\end{array}$} & model: & $\begin{array}{c}\mathrm{W}[\mathrm{D} 1] \mathrm{IS} \\
{[\mathrm{N}]} \\
\mathrm{IS}[\mathrm{D} 1] \mathrm{W} \\
\end{array}$ & $\begin{array}{c}\mathrm{W}[\mathrm{D} 2] \mathrm{IS} \\
{[\mathrm{N}]} \\
\mathrm{IS}[\mathrm{D} 2] \mathrm{W}\end{array}$ & $\begin{array}{c}\mathrm{W}[\mathrm{D} 4] \mathrm{IS} \\
{[\mathrm{N}]} \\
\mathrm{IS}[\mathrm{D} 3] \mathrm{W}\end{array}$ & $\begin{array}{c}\text { W[D5]IS } \\
{[\mathrm{N}]} \\
\text { IS[D5]W }\end{array}$ & $\begin{array}{c}\text { W[D6]IS } \\
{[\mathrm{N}]} \\
\text { IS[D6]W }\end{array}$ \\
\hline & figure: & 7a) & 7b) & 7c) & 7d) & 7e) \\
\hline \multirow{5}{*}{ W[Di] } & ${ }^{23} \mathrm{NaS}$ & - & - & $+38.6 \pm 0.00$ & - & - \\
\hline & ${ }^{23} \mathrm{Na} /{ }^{l} H C$ & - & $+14.8 \pm 0.00$ & $-4.9 \pm 0.00$ & $-9.8 \pm 0.00$ & $+4.2 \pm 3.9$ \\
\hline & ${ }^{29} \mathrm{Si}$ & $-99.4 \pm 2.02$ & $-100.3 \pm 0.45$ & $-94.1 \pm 0.93$ & $-94.5 \pm 0.92$ & $-93.9 \pm 1.20$ \\
\hline & ${ }^{1} \mathrm{H}$ & $+1.1 \pm 0.15$ & $+0.63 \pm 0.00$ & $-1.0 \pm 0.36$ & $-0.18 \pm 0.5$ & $-0.04 \pm 0.31$ \\
\hline & ${ }^{25} \mathrm{Mg}$ & $+29.9 \pm 6.24$ & $+35.5 \pm 12.1$ & $+20.8 \pm 1.02$ & $+19.7 \pm 0.78$ & $+19.8 \pm 1.1$ \\
\hline \multirow{5}{*}{ [Di]IS } & ${ }^{23} \mathrm{NaS}$ & - & - & $+38.6 \pm 0.00$ & - & - \\
\hline & ${ }^{23} \mathrm{Na} /{ }^{1} H C$ & $+16.9 \pm 0.00$ & - & - & $-0.08 \pm 0.00$ & $+4.8 \pm 1.6$ \\
\hline & ${ }^{29} \mathrm{Si}$ & $-95.1 \pm 0.36$ & $-117.0 \pm 14.2$ & $-97.3 \pm 0.35$ & $-93.7 \pm 0.32$ & $-95.9 \pm 0.53$ \\
\hline & ${ }^{1} \mathrm{H}$ & $-0.36 \pm 0.00$ & $+7.7 \pm 2.2$ & $+0.11 \pm 0.24$ & $+0.17 \pm 0.69$ & $+0.42 \pm 0.00$ \\
\hline & ${ }^{25} \mathrm{Mg}$ & $+29.9 \pm 6.24$ & $+35.5 \pm 12.1$ & $+20.8 \pm 1.02$ & $+19.7 \pm 0.78$ & $+19.8 \pm 1.1$ \\
\hline \multirow{5}{*}{ IS[Dj] } & ${ }^{23} \mathrm{NaS}$ & - & - & $+42.2 \pm 0.00$ & - & - \\
\hline & ${ }^{23} \mathrm{Na} /{ }^{l} H C$ & $+16.8 \pm 0.00$ & - & $-3.6 \pm 0.00$ & $-0.57 \pm 0.00$ & $+5.1 \pm 1.4$ \\
\hline & ${ }^{29} \mathrm{Si}$ & $-95.1 \pm 0.36$ & $-117.2 \pm 14.2$ & $-93.7 \pm 0.34$ & $-93.4 \pm 0.23$ & $-97.8 \pm 0.47$ \\
\hline & ${ }^{1} \mathrm{H}$ & $-0.22 \pm 0.00$ & $+7.7 \pm 2.4$ & $-0.69 \pm 0.41$ & $+0.11 \pm 0.59$ & $+1.11 \pm 0.00$ \\
\hline & ${ }^{25} \mathrm{Mg}$ & $+29.3 \pm 5.18$ & $+35.6 \pm 12.2$ & $+21.0 \pm 0.29$ & $+19.7 \pm 0.63$ & $+19.5 \pm 1.03$ \\
\hline \multirow{5}{*}[\mathrm{Dj}]{$\mathrm{W}$} & ${ }^{23} \mathrm{NaS}$ & - & - & $+42.2 \pm 0.00$ & - & - \\
\hline & ${ }^{23} \mathrm{Na} /{ }^{1} H C$ & - & $+1.3 \pm 0.00$ & - & $+2.6 \pm 0.00$ & $+5.4 \pm 2.1$ \\
\hline & ${ }^{29} \mathrm{Si}$ & $-99.4 \pm 2.02$ & $-100.1 \pm 0.28$ & $-97.2 \pm 1.43$ & $-93.9 \pm 0.67$ & $-95.6 \pm 0.53$ \\
\hline & ${ }^{1} \mathrm{H}$ & $+1.1 \pm 0.15$ & $+0.41 \pm 0.00$ & $+0.02 \pm 0.16$ & $-0.09 \pm 0.71$ & $+0.54 \pm 0.00$ \\
\hline & ${ }^{25} \mathrm{Mg}$ & $+29.3 \pm 5.18$ & $+35.6 \pm 12.2$ & $+21.0 \pm 0.29$ & $+19.7 \pm 0.63$ & $+19.5 \pm 1.03$ \\
\hline \multirow{3}{*}[\mathrm{N}]{} & ${ }^{29} \mathrm{Si}$ & $-98.3 \pm 0.93$ & $-98.2 \pm 0.31$ & $-98.4 \pm 1.7$ & $-98.2 \pm 1.09$ & $-97.9 \pm 1.2$ \\
\hline & ${ }^{1} \mathrm{H}$ & $+0.51 \pm 0.08$ & $+0.33 \pm 0.04$ & $+0.71 \pm 0.36$ & $+0.78 \pm 0.07$ & $+0.79 \pm 0.21$ \\
\hline & ${ }^{25} \mathrm{Mg}$ & $+21.1 \pm 0.17$ & $+21.4 \pm 0.09$ & $+21.7 \pm 0.11$ & $+21.6 \pm 0.13$ & $+21.5 \pm 0.04$ \\
\hline
\end{tabular}

${ }^{a}$ Values reported are averages, and average deviations for the various nuclei. 
The final configurations obtained for these models and illustrated on Figure 7a-e need the following precisions in order to be fully appraised:

W[D1]IS[N]IS[D1]W : in the two defective TOT layers, the structural OH groups initially replaced by $\mathrm{ONa}$ ( $\mathrm{Na}$ on IS side) produce an indirect expulsion of $\mathrm{O}$ atoms towards the water phase by reconstruction of the layers, leaving $\mathrm{Na}^{+}$ions still in IS close to the center of a hexagonal window, facing a vacant $\mathrm{OH}$ site. $2 \mathrm{H}_{2} \mathrm{O}_{2}$ molecules are formed in the water layer. The $6 \mathrm{Mg}^{2+}$ ions vicinal to those sites in the 2 defective layers have $\delta{ }^{25} \mathrm{Mg}=+35.3 \pm 1.97 \mathrm{ppm}$, while the other $6 \mathrm{Mg}^{2+}$ ions have nearly normal $\delta{ }^{25} \mathrm{Mg}=+23.9 \pm 0.28 \mathrm{ppm}$. Under-coordinated $\mathrm{Mg}^{2+}$ ions are therefore significantly unshielded.

W[D2]IS[N]IS[D2]W : in the two defective TOT layers, the structural OH groups initially replaced by $\mathrm{ONa}$ ( $\mathrm{Na}$ on water side) produce an extraction of $\mathrm{ONa}$ groups towards the water phase, resulting in solvated $\mathrm{Na}^{+}$ions and a vacant $\mathrm{OH}$ site facing the water layer. The 6 undercoordinated $\mathrm{Mg}^{2+}$ ions vicinal to those sites in the 2 defective layers are highly unshielded with $\delta{ }^{25} \mathrm{Mg}=+47.7 \pm 1.14$, while the other $6 \mathrm{Mg}^{2+}$ ions have nearly normal $\delta{ }^{25} \mathrm{Mg}=+23.4 \pm$ $0.63 \mathrm{ppm}$. The two $\mathrm{Na}^{+}$ions end up solvated but not to the same extent: the average $\mathrm{Na}-\mathrm{O}$ distance for $\mathrm{Na}$ which has $\delta^{23} \mathrm{Na}=+14.8 \mathrm{ppm}$ is $0.229 \pm 0.004 \mathrm{~nm}$ (W[D2]), while that for $\mathrm{Na}$ which has $\delta^{23} \mathrm{Na}=+1.3 \mathrm{ppm}$ is $0.245 \pm 0.010 \mathrm{~nm}$ ([D2]W). The first is 6-fold coordinated to 5 water molecules plus one bridging $\mathrm{O}$ of the defective TOT interface, while the second one is 5fold coordinated to 5 water molecules far from the interface. This model W[D2]IS[N]IS[D2]W is more stable by circa $3.25 \mathrm{eV}$ than model W[D1]IS[N]IS[D1]W after full relaxations.

W[D5]IS[N]IS[D5]W: for this model, we obtain $\delta{ }^{1} \mathrm{H}=+0.32 \mathrm{ppm}$ for the proton of the structural $\mathrm{OH}$ interacting with the compensation $\mathrm{Na}^{+}$at $\delta{ }^{23} \mathrm{Na}=-9.8 \mathrm{ppm} . \mathrm{A} \mathrm{H}_{2} \mathrm{O}-\mathrm{Na}^{+} \cdots \cdot \mathrm{OH}$ adsorbed structure is formed (see Figure 8, defect W[D5]). In contrast, we obtain $\delta^{1} \mathrm{H}=+0.62$ 
ppm for the proton of the structural $\mathrm{OH}$ interacting with the compensation $\mathrm{Na}^{+}$at $\delta{ }^{23} \mathrm{Na}=+2.6$ ppm and in that configuration a $\mathrm{H}_{2} \mathrm{O}-\mathrm{Na}^{+} \ldots \cdot \mathrm{OH}$ adsorbed structure is not formed.

W[D6]IS[N]IS[D6]W : For this model, each compensation proton binds to a structural $\mathrm{OH}$ producing a structural water molecule with deshielded protons $\left(\delta{ }^{1} \mathrm{H} \sim+5 \mathrm{ppm}\right)$. Notice that the geometry optimization of this model by DFT did not end into a fully symmetric configuration. Indeed, while the compensation protons do produce two structural water molecules at the IS [D6] interface (Figure 7e right hand side defective TOT), only one appears at the [D6]IS interface and the other compensation proton has been captured by a bulk water molecule to form a compensating hydronium $\mathrm{H}_{3} \mathrm{O}^{+}$at the W[D6] interface. This effective proton transfer supports a moderate Brönsted acidity to be expected from such defective nanotalc basal planes, with consequences for instance on their catalytic properties.

From the examination of Table 3 we can draw the following conclusions:

(1) The close similarity of average chemical shifts for all nuclei of [N] layers confirms that they are hardly influenced by defects in adjacent layers and IS. Some influence however is perceptible from the larger average deviations on $\delta{ }^{1} \mathrm{H}$ and $\delta{ }^{29} \mathrm{Si}$ than for an ideal bulk model (Table 2, line 7).

(2) Models W[D1]IS[N]IS[D1]W and W[D2]IS[N]IS[D2]W can be ruled out since the deep restructuration following the extraction of $\mathrm{O}^{-}$ions from $\mathrm{Mg}^{2+}$ coordination spheres in the interfacial $\mathrm{O}$ layers affects predicted chemical shifts to an extent incompatible with observations. At least, these models provide references for chemical shifts of hydrated $\mathrm{Na}^{+}$ cations.

(3) Model W[D4]IS[N]IS[D3]W explains rather well observations of $\delta^{23} \mathrm{Na}=+46 \mathrm{ppm}, \delta^{23} \mathrm{Na}$ $=-5 \mathrm{ppm}, \delta{ }^{29} \mathrm{Si}=-95 \mathrm{ppm}$, but not signals at $\delta{ }^{1} \mathrm{H}=+0.2 \mathrm{ppm}$ and $\delta{ }^{23} \mathrm{Na}=-16 \mathrm{ppm}$ and the intercorrelations of the latter with the signal at $\delta{ }^{29} \mathrm{Si}=-95 \mathrm{ppm}$. It must therefore be also ruled 
out for the latter. However, since it predicts $\delta{ }^{1} \mathrm{H}$ signals between -0.6 and -1 ppm which are effectively observed although very weak, this model may account for a part of the low overall amount of residual $\mathrm{Na}$ in our washed samples. The absence of correlation between $\delta{ }^{23} \mathrm{Na}=-$ $5.0 \mathrm{ppm}$ and $\delta{ }^{1} \mathrm{H}=-0.6 \mathrm{ppm}$ in the HETCOR map (Figure 4c) may result from the significant mobility of the corresponding hydratable species at the water/basal planes interfaces.

(4) Model W[D5]IS[N]IS[D5]W is the first one explaining all observed signals, particularly providing a consistent semi-quantitative interpretation of the correlations between signals at $\delta$ ${ }^{23} \mathrm{Na}=-16 \mathrm{ppm}, \delta^{29} \mathrm{Si}=-95 \mathrm{ppm}$ and $\delta{ }^{1} \mathrm{H}=+0.2 \mathrm{ppm}$ : The configuration of the defect involved on the W[D5] side is graphically represented on Figure 8. The frustrated configuration of an ion $\left(\mathrm{H}_{2} \mathrm{O}\right)_{2}-\mathrm{Na}^{+}$adsorbed above the center of a basal hexagonal window, and interacting with the corresponding structural $\mathrm{OH}$ group in partial charge compensation for the underlying $\mathrm{Mg}^{2+}$ vacancy indeed induces both $\mathrm{Na}$ shielding to ${ }^{23} \mathrm{Na}=-9.8 \mathrm{ppm}$ and a slight increase of $\mathrm{H}$ shielding, since the interacting $\mathrm{OH}$ group becomes more basic, akin to that in aqueous $\mathrm{NaOH}$. This model introduces a direct effect of the water face at the interface. Our simulations were merely geometry optimizations to the closest energy minimum at $0 \mathrm{~K}$ : molecular dynamics at synthesis or ambient temperature would explore more exhaustively the configurational space, allowing for instance anharmonic vibrational elongation of the $\mathrm{Na}^{+}---\mathrm{OH}$ bond and it is thus possible to understand that the experimental signal $\delta{ }^{23} \mathrm{Na}$ for this particular site is even more shielded. Another explanation that can justify the difference between the theoretical and experimental values obtained for the $-16 \mathrm{ppm}$ signal consists in taking into account the quadripolar character of the $\mathrm{Na}$ nuclei, which may moves the experimental chemical shift towards lower values, whereas DFT calculations measure the theoretical isotropic value.

(5) Model W[D6]IS[N]IS[D6]W should be also considered, since while the D6 defects induce $\delta^{29} \mathrm{Si}=-95 \mathrm{ppm}$ shifts for $\mathrm{Q}^{3} \mathrm{Si}$ in the interfacial layers, charge compensation protons binding to structural $\mathrm{OH}$ groups and producing a "structural water molecule" will not be differentiated 
from the contribution of other water species in the samples. Some correlation should however be observed by HETCOR between the two signals in that case, but again water mobility might induce signals decorrelation. The main interest of this particular model is to explain the quite significant fraction of $\mathrm{Q}^{3} \mathrm{Si}$ shifted at $-95 \mathrm{ppm}$ even for very low $\mathrm{Na}$ content in washed samples (e.g. $\mathrm{Na} / \mathrm{Si}$ circa 0.01$)$.

Table 4 provides an analysis of $\mathrm{Na}-\mathrm{O}$ distances lower than $0.300 \mathrm{~nm}$ for different environments of $\mathrm{Na}^{+}$obtained from our DFT simulations and characterized as shielded (negative $\delta^{23} \mathrm{Na}$ ) to highly deshielded (positive $\delta^{23} \mathrm{Na}$ ). Figure 8 depict these various situations. Although some anticorrelation appears between the as defined coordination number $\mathrm{Z}_{\mathrm{NaO}}$ and shielding, it appears that geometrical considerations alone cannot describe the trend trustfully. Indeed, as well known, shielding driven by induced electronic currents around nuclei depends subtly on electronic structure, therefore on the symmetry and more or less delocalized character of orbitals contributing to the wavefunction.

Table 4. Analysis of the First Coordination Spheres of $\mathrm{Na}^{+}$for the Situations Illustrated on Figure 10. Distances are given in $\mathbf{n m}$

\begin{tabular}{|c|c|c|c|c|c|c|}
\hline site: & $\mathrm{W}[\mathrm{D} 5]$ & $\mathrm{W}[\mathrm{D} 4]$ & [D5]IS & $\mathrm{W}[\mathrm{D} 2]^{\mathrm{a}}$ & {$[\mathrm{D} 2] \mathrm{W}^{\mathrm{b}}$} & [D3] \\
\hline $\begin{array}{l}\delta^{23} \mathrm{Na} \\
(\mathrm{ppm})\end{array}$ & -9.8 & -4.8 & -0.08 & +1.3 & +14.8 & +42.2 \\
\hline d1 & $0.229\left(\mathrm{Na}-\mathrm{OH}_{2}\right)$ & $0.214\left(\mathrm{Na}-\mathrm{OH}_{2}\right)$ & $0.234(\mathrm{Na}-\mathrm{OH})$ & $0.232\left(\mathrm{Na}-\mathrm{OH}_{2}\right)$ & $0.224\left(\mathrm{Na}-\mathrm{OH}_{2}\right)$ & $0.214(\mathrm{Na}-\mathrm{OH})$ \\
\hline $\mathrm{d} 2$ & $0.246\left(\mathrm{Na}-\mathrm{OH}_{2}\right)$ & $0.227\left(\mathrm{Na}-\mathrm{OH}_{2}\right)$ & $0.244\left(\mathrm{Na}-\mathrm{OSi}_{2}\right)$ & $0.237\left(\mathrm{Na}-\mathrm{OH}_{2}\right)$ & $0.226\left(\mathrm{Na}-\mathrm{OH}_{2}\right)$ & $0.248(\mathrm{Na}-\mathrm{OH})^{\mathbf{c}}$ \\
\hline $\mathrm{d} 3$ & $0.281(\mathrm{Na}-\mathrm{OH})$ & & & $0.241\left(\mathrm{Na}-\mathrm{OH}_{2}\right)$ & $0.226\left(\mathrm{Na}-\mathrm{OH}_{2}\right)$ & \\
\hline $\mathrm{d} 4$ & $0.249\left(\mathrm{Na}-\mathrm{OSi}_{2}\right)$ & $0.257\left(\mathrm{Na}-\mathrm{OSi}_{2}\right)$ & $0.243\left(\mathrm{Na}-\mathrm{OSi}_{2}\right)$ & $0.243\left(\mathrm{Na}-\mathrm{OH}_{2}\right)$ & $0.228\left(\mathrm{Na}-\mathrm{OH}_{2}\right)$ & $0.214(\mathrm{Na}-\mathrm{OMg})$ \\
\hline d5 & $0.258\left(\mathrm{Na}-\mathrm{OSi}_{2}\right)$ & $0.271\left(\mathrm{Na}-\mathrm{OSi}_{2}\right)$ & $0.244\left(\mathrm{Na}-\mathrm{OSi}_{2}\right)$ & $0.252\left(\mathrm{Na}-\mathrm{OH}_{2}\right)$ & $0.238\left(\mathrm{Na}-\mathrm{OH}_{2}\right)$ & $0.215(\mathrm{Na}-\mathrm{OMg})$ \\
\hline d6 & $0.270\left(\mathrm{Na}-\mathrm{OSi}_{2}\right)$ & $0.282\left(\mathrm{Na}-\mathrm{OSi}_{2}\right)$ & $0.246\left(\mathrm{Na}-\mathrm{OSi}_{2}\right)$ & & - & $0.225(\mathrm{Na}-\mathrm{OMg})$ \\
\hline d7 & $0.279\left(\mathrm{Na}-\mathrm{OSi}_{2}\right)$ & $0.291\left(\mathrm{Na}-\mathrm{OSi}_{2}\right)$ & $0.272\left(\mathrm{Na}-\mathrm{OSi}_{2}\right)$ & $0.261\left(\mathrm{Na}-\mathrm{OSi}_{2}\right)$ & - & $0.226(\mathrm{Na}-\mathrm{OMg})$ \\
\hline $\mathrm{d} 8$ & $0.287\left(\mathrm{Na}-\mathrm{OSi}_{2}\right)$ & $0.292\left(\mathrm{Na}-\mathrm{OSi}_{2}\right)$ & $0.278\left(\mathrm{Na}-\mathrm{OSi}_{2}\right)$ & - & - & \\
\hline d9 & $0.297\left(\mathrm{Na}-\mathrm{OSi}_{2}\right)$ & - & $0.283\left(\mathrm{Na}-\mathrm{OSi}_{2}\right)$ & - & - & - \\
\hline $\mathrm{Z}_{\mathrm{NaO}}$ & 9 & 7 & 8 & 6 & 5 & 6 \\
\hline$<\mathrm{d} \mathrm{NaO}>$ & 0.266 & 0.262 & 0.256 & 0.244 & 0.229 & 0.224 \\
\hline $\begin{array}{l}<\mathrm{d} \mathrm{NaO}> \\
\text { intervals }\end{array}$ & 0.022 & 0.031 & 0.019 & 0.077 & 0.052 & 0.013 \\
\hline
\end{tabular}


${ }^{a}$ Distances are given in $\mathrm{nm}$. Coordination spheres are arbitrarily limited to a cutoff distance of

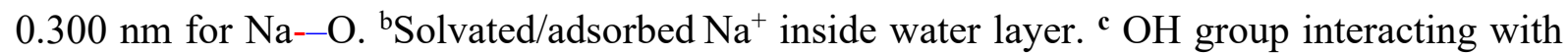
compensation $\mathrm{Na}^{+}$in IS.

a)

b)

Site W[D5]
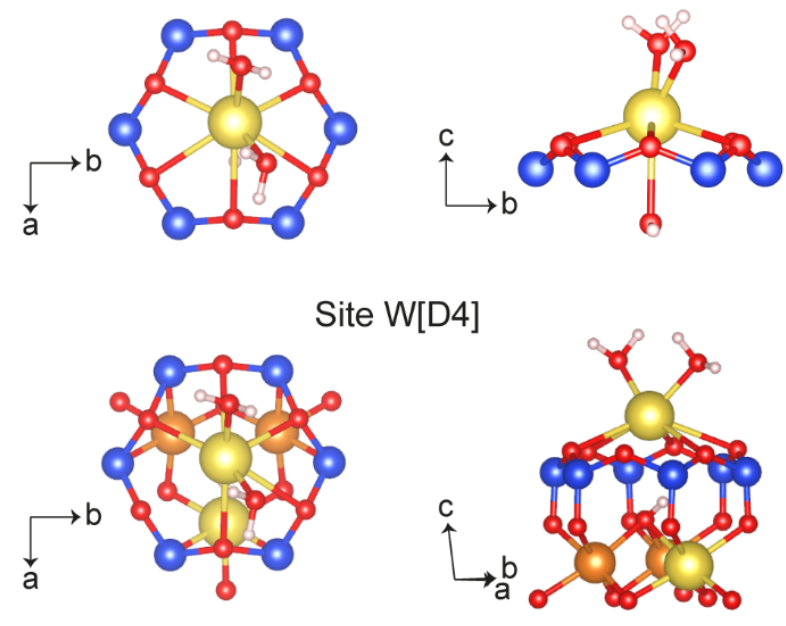

Site [D5]IS


Site W[D2]
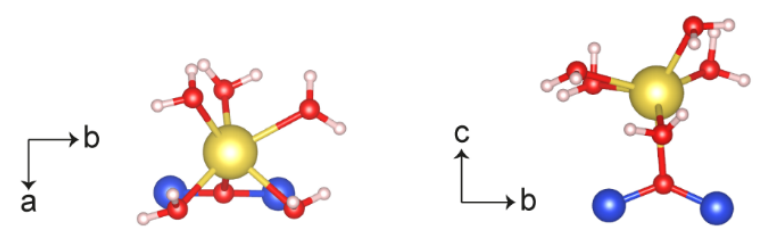

Site [D3]
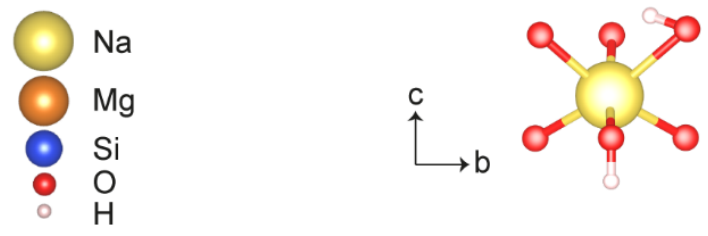

Figure 8. Types of Na defects: (a) top view; (b) side view. W[D5]: See Table 3 column 4, Figure 7d, and Table 4 column 1; W[D4]: See Table 3 column 3, Figure 7c and Table 4 column 
2; [D5]IS: See Table 3 column 3, Figure 7d and Table 4 column 3; W[D2]: See Table 3 column 2, Figure 7b, and Table 4 column 4; [D3]: See Table 3 column 3, Figure 7c and Table 4 column 6.

Fully Hydrated $\{130\}$ and $\{100\}$ Talc Edge Planes. We merely summarize the results reported elsewhere $^{40}$ in order to facilitate the discussion which follows. Figures S5 and S6 present the configurations obtained for the fully hydrated $\{130\}$ and $\{100\}$ edge planes expressed together with the $\{001\}$ basal planes (hydrophobic if defectless) and the symmetry related facets in the equilibrium morphology in presence of liquid water and $600 \mathrm{~K}$ ( $\sim$ synthesis temperature). This morphology is shown on Figure 9. The two facets $\{001\}$ contribute for $85.23 \%$, the four facets $\{130\}$ for $8.79 \%$, and the two facets $\{100\}$ for $5.98 \%$ to a particle surface area. A particle at equilibrium morphology has dimensions $\mathrm{L}_{1} / \mathrm{e}=8.176$ and $\mathrm{L}_{2} / \mathrm{e}=6.013$ relative to its thickness e, where $L_{1}$ is the length of a $\{100\}$ facet and $L_{2}$ that of a $\{130\}$ facet. Noteworthy, areal densities of Si for these surfaces are 8.3560, 2.3617 and $2.3368 \mathrm{Si}^{-\mathrm{nm}^{-2}}$ for $\{001\},\{130\}$ and $\{100\}$ respectively. Table 5 collects the predicted chemical shifts for these two models and nuclei ${ }^{1} \mathrm{H},{ }^{29} \mathrm{Si}$ and ${ }^{25} \mathrm{Mg}$.

a)
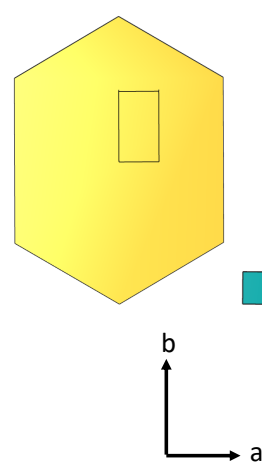

b)
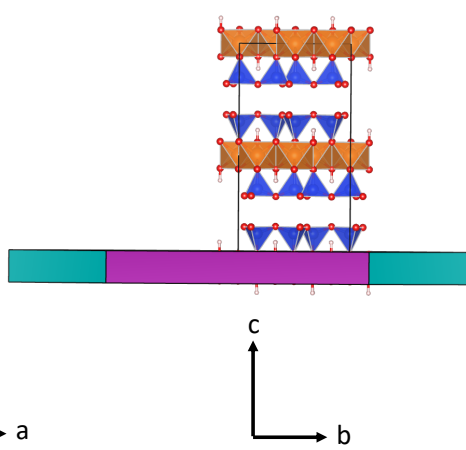

c)

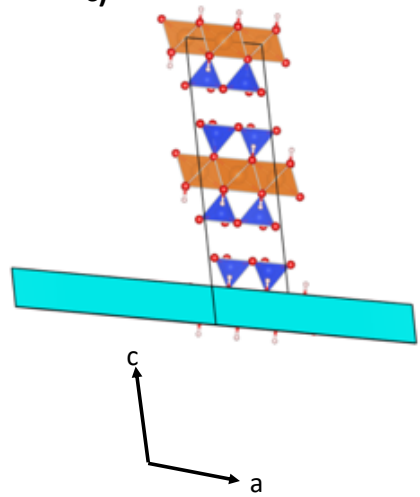

d)

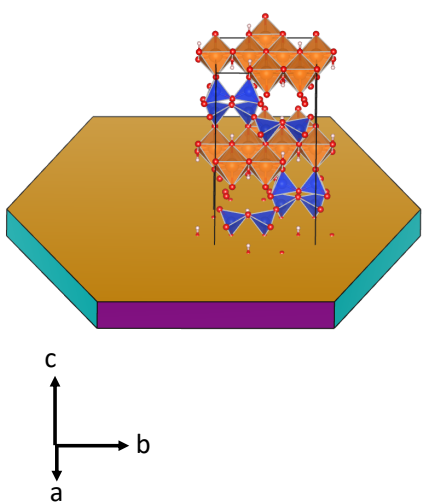

Figure 9. Equilibrium morphology of a fully hydrated talc crystallite at synthesis temperature (600K): (a) view along $-\vec{c}$ axis; (b) view along $-\vec{a}$ axis; (c) view along $\vec{b}$ axis; (d) perspective view. Color code: facets $\{001\}$ orange, facets $\{130\}$ blue, facets $\{100\}$ purple; tetrahedrons $T$ 
in TOT layers dark blue, octahedrons O in TOT layers orange, oxygen atoms red, hydrogen atoms light grey.

Chizallet et al. ${ }^{43}$ in a DFT study of clusters modelling surface sites of hydroxylated $\mathrm{MgO}$ found ${ }^{1} \mathrm{H}$ NMR shifts between +0.4 and +0.7 ppm for "corner sites" (“O3C-H”) exhibiting hydroxyls bonded to $3 \mathrm{Mg}$ ions similarly to bulk hydroxyls in talc: this prediction coincides with our result reported in Table 5 and with experiment in that case. For their models $\mathrm{O} 1 \mathrm{C}-\mathrm{H}$ and $\mathrm{O} 2 \mathrm{C}-\mathrm{H}$ where hydroxyls are bonded to 1 and $2 \mathrm{Mg}$ ions, ${ }^{1} \mathrm{H}$ NMR shifts decrease between 0 and -0.9 ppm, an opposite trend to that we found for 2-fold or 1-fold coordinated edge hydroxyls inherited from bulk 3-fold coordinated in our talc slab models. We can only conclude that it is not possible to extract analogical trends from the comparison of models with such significant structural and chemical differences.

Table 5. Predicted Average Chemicals Shifts in ppm for Fully Hydrated $\{130\}$ and $\{100\}$ Talc Edge Planes Model (Adapted with permission from ref. 40 Copyright (2019) ACS)

\begin{tabular}{lcc}
\multicolumn{1}{c}{ edge model } & $\{130\}$ & $\{100\}$ \\
$\delta^{29} \mathrm{Si}$ bulk $\left(\mathrm{Q}^{3}\right)$ & $-98.6 \pm 0.33$ & $-96.4 \pm 0.49$ \\
$\delta^{29} \mathrm{Si}$ edge $\mathrm{Si}^{*}-\mathrm{OH}\left(\mathrm{Q}^{2}\right)$ & $-87.4 \pm 0.22$ & $-85.6 \pm 1.02$ \\
$\delta{ }^{1} \mathrm{H}$ bulk $\mathrm{Mg}_{3}-\mathrm{OH}^{*}$ & $+0.67 \pm 0.06$ & $+0.30 \pm 0.08$ \\
$\delta{ }^{1} \mathrm{H}$ edge $\mathrm{Si}_{-}-\mathrm{OH}^{*}$ & $+2.03 \pm 0.37$ & $+2.02 \pm 0.46$ \\
$\delta{ }^{1} \mathrm{H}$ edge $\mathrm{Mg}_{2}-\mathrm{OH}^{*}$ & $+1.51 \pm 0.49$ & $+0.82 \pm 0.30$ \\
$\delta{ }^{1} \mathrm{H}$ edge $\mathrm{Mg}-\mathrm{OH}_{2} *$ & $+4.79 \pm 1.8$ & $+4.90 \pm 1.68$ \\
$\delta^{25} \mathrm{Mg}$ bulk & $+17.7 \pm 0.37$ & $+19.7 \pm 0.27$ \\
$\delta^{25} \mathrm{Mg}$ edge $\mathrm{Mg}^{*}-\mathrm{OH}_{2}$ & $+16.7 \pm 1.10$ & $+20.1 \pm 0.24$
\end{tabular}

\section{DISCUSSION}

Overall Structuration of the Synthetic Talc Nanoparticles. The experimental study carried out on the series of synthetic talc samples, as well as the results obtained by DFT calculations enable to get insights on the structure of the material: the particles are composed of a mixture 
of nano-sized defective TOT layers and non-defective TOT layers which explain the various contributions observed in the ${ }^{1} \mathrm{H},{ }^{29} \mathrm{Si}$ and ${ }^{23} \mathrm{Na}$ NMR spectra (Figure 10).

a)

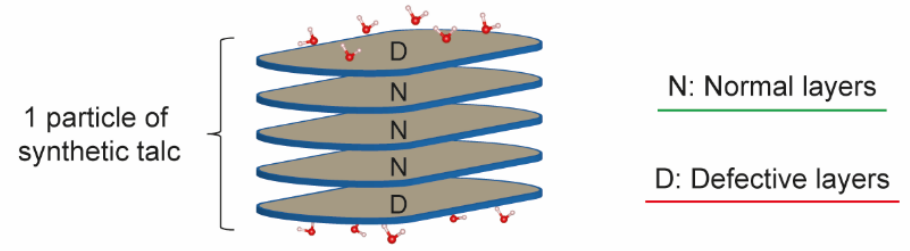

b)

${ }^{1} \underline{\mathrm{H} N M R}$

${ }^{29} \underline{\mathrm{SiNMR}}$

${ }^{23} \underline{\mathrm{Na} \mathrm{NMR}}$
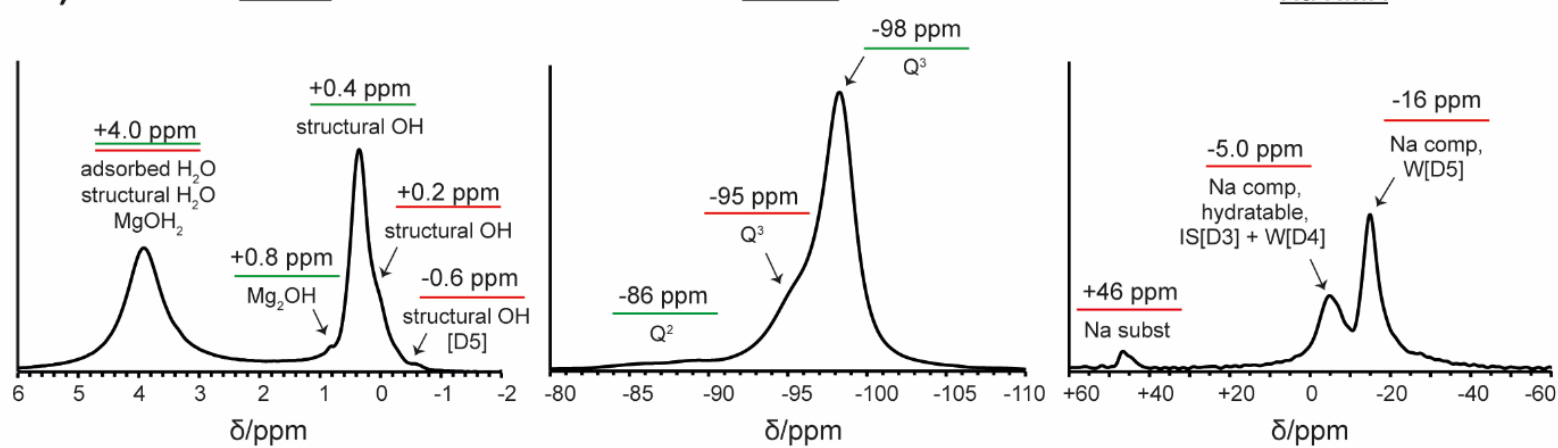

Figure 10. (a) Overall structuration of the talc particles, (b) NMR signals of normal and defective layers.

As well known in crystalline growth phenomena, the defective layers are in all likelihood rejected at interfaces, and therefore located on the external parts of the particles, whereas the normal ones are internal. The defects are of different natures ( $\mathrm{Na}$ substitutions, $\mathrm{Mg}$ vacancies), and the proportion of defective layers decreases when the particles crystallinity increases (that is to say when the duration of synthesis increases). This shows the "curative" effect provided by the hydrothermal treatment. In the same manner, the lower crystallized fraction of a sample (i.e. smaller particles) is richer in defects than the better crystallized fraction of the same sample (i.e. larger particles). This was evidenced on a synthetic talc sample of 2 weeks of synthesis where the fine and coarse fractions were isolated (ST-2W-F and ST-2W-C respectively) and analyzed by ${ }^{29} \mathrm{Si} \mathrm{NMR}$. The results are presented on Figure 11 and compared to the undivided fraction (ST-2W-mix). As expected, the finer fraction shows a larger proportion of defective 
layers than the coarser one, as evidenced by the higher proportion of $\mathrm{Q}^{3}$ environments at -95 ppm, which we will denote further $\mathrm{PQ}^{3}$ for Perturbed $\mathrm{Q}^{3}$.



Figure 11. ${ }^{29} \mathrm{Si}$ MAS-NMR spectra of the fine and coarse fractions of a synthetic talc of two weeks of synthesis.

\section{Re-Assignation of the Observed ${ }^{1} \mathrm{H},{ }^{29} \mathrm{Si}$ and ${ }^{23} \mathrm{Na}$ NMR Shifts and their Correlations on}

the Basis of DFT Calculations. The representation of all of the different plausible structural configurations of the synthetic talc particles and their corresponding NMR chemical shifts are reported on Figures 10 and 12 . The non-defective layers present bulk signals at $-98 \mathrm{ppm}$ in ${ }^{29} \mathrm{Si}$ $\left(\mathrm{Q}^{3}\right.$ species $)$ and $+0.4 \mathrm{ppm}$ in ${ }^{1} \mathrm{H}($ structural $\mathrm{OH})$ whereas the defective layers display bulk signals at $-95 \mathrm{ppm}\left(\mathrm{PQ}^{3}\right)$ and $+0.2 \mathrm{ppm}$. Since these two groups of species are spatially close to one another in the layers, this explains the correlation zones that are observed in the $2 \mathrm{D}\left\{{ }^{1} \mathrm{H}\right\}-$ ${ }^{29} \mathrm{Si}$ HETCOR spectrum (Figure $\left.4 \mathrm{a}\right)$. 


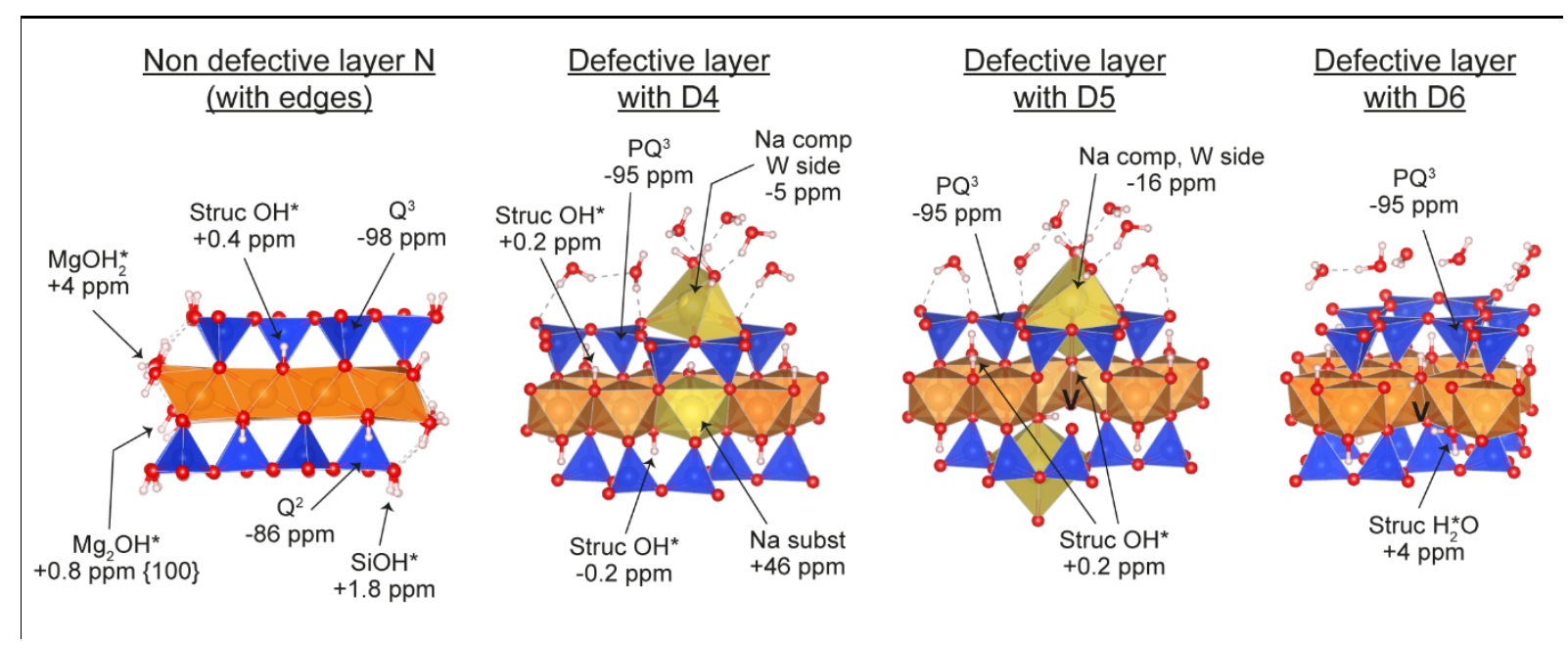

Figure 12. Summary of the various structural configurations present in synthetic talc and their corresponding ${ }^{1} \mathrm{H},{ }^{29} \mathrm{Si}$ and ${ }^{23} \mathrm{Na} \mathrm{NMR}$ signals (V: vacancy).

The DFT approach also enabled to identify the three types of $\mathrm{Na}^{+}$species that are present in the defective layers (Figure 2c). The first one resonating at $+46 \mathrm{ppm}$ correspond to $\mathrm{Na}^{+}$ cations substituting $\mathrm{Mg}^{2+}$ cations in the octahedral layer (defects D3 and D4). This environment becomes more and more important when the particles crystallinity increases, testifying the extension of the particles in the (ab) plane. The correlation with $\mathrm{H}$ species observed at $-0.2 \mathrm{ppm}$ (Figure 4c) probably indicates that the latter correspond to structural $\mathrm{OH}$ groups coming from the immediate environment of the $\mathrm{Na}$ octahedra. Although this correlation is not exactly reproduced by the DFT models (Table 3, defects D3 and D4), the $\delta^{1} \mathrm{H}$ is still strongly shifted towards lower values compared to a normal TOT layer. The negative charge generated by the substitution of $\mathrm{Mg}^{2+}$ by $\mathrm{Na}^{+}$is compensated by $\mathrm{Na}^{+}$ions either in the interlayer space or in the external water/TOT interface, resulting in a second $\mathrm{Na}^{+}$signal around $-5.0 \mathrm{ppm}$ (Table 3, defects W[D4] and IS[D3]). However, the fact that this signal gradually decreases with increasing synthesis time (Figure 2c), and therefore increasing particle size, suggests that the $\mathrm{Na}^{+}$ions are rather located at the water/TOT interface rather than in the IS; otherwise, their relative abundance would remain stable whatever the sample's crystallinity. In such a configuration, the structural $\mathrm{OH}$ groups located to the closest position of the defects resonate at around -0.6 
ppm, what is mostly confirmed by the DFT calculations. Finally, the third type of $\mathrm{Na}^{+}$species resonating at around $-16 \mathrm{ppm}$ are interpreted as 9-fold coordinated $\mathrm{Na}^{+}$ions located above the center of a Si tetrahedra hexagonal cavity, which interact with 2 water molecules at the interface and one underlying structural $\mathrm{OH}$ group, and which compensate a $\mathrm{Mg}^{2+}$ vacancy in the octahedral layer (defect D5). These third species are thus proximate to structural OH groups (resonating at $+0.2 \mathrm{ppm}$ ) and $\mathrm{PQ}^{3}$-type $\mathrm{Si}$ (resonating at $-95 \mathrm{ppm}$ ) which justifies the correlations observed in the Figure $4 \mathrm{~b}$, c. When comparing these interpretations with our first assignments based on Cattaneo et al. ${ }^{39}$, it appears that only the assignment of the octahedral $\mathrm{Na}^{+}$environment is maintained $\left(\delta^{23} \mathrm{Na}=+46 \mathrm{ppm}\right)$. Indeed, in the two other cases $\left(\delta^{23} \mathrm{Na}=-5.0\right.$ and $-16 \mathrm{ppm}$ ), the $\mathrm{Na}^{+}$ions correspond rather to external species located at the water/particle interface than to exchangeable $\mathrm{Na}^{+}$species located inside the IS, like reported by Cattaneo et al. ${ }^{39}$ on fluoromicas. However, it is noteworthy that the sole presence of $\mathrm{Na}^{+}$ions cannot explain all of the defective layers present in the samples otherwise the percentage of Na recorded in the microprobe analysis would be much greater than $1 \mathrm{wt} . \%$. Another model excluding any type of $\mathrm{Na}^{+}$ion must then be considered, and the model W[D6]IS[N]IS[D6]W is a good candidate for that. As a reminder, this model involves D6 defects, meaning $\mathrm{Mg}^{2+}$ vacancies compensated by $\mathrm{H}^{+}$ions on either side of the structure and which bind to adjacent structural $\mathrm{OH}$ groups to form internal water molecules (Figure 12, defect D6). This model is particularly relevant because $\mathrm{H}^{+}$ ions may form during the formation of the defective talc layers by reaction between talc precursor entities and acetic acid, following this equation: $\mathrm{Si}_{4} \mathrm{Mg}_{3} \mathrm{O}_{10}(\mathrm{OH})_{2}+2 \mathrm{CH}_{3} \mathrm{COOH} \rightarrow$ $\mathrm{Si}_{4} \mathrm{Mg}_{2} \mathrm{O}_{10}(\mathrm{OH})_{2}+\left(\mathrm{CH}_{3} \mathrm{COO}\right)_{2} \mathrm{Mg}+2 \mathrm{H}^{+}$. In such case, the formation of structural water molecules would produce a ${ }^{1} \mathrm{H}$ NMR signal at around 4.0-5.0 ppm, which would merge with the signal of adsorbed water on the particles edges. This type of defective layer is thus probably the most widespread in the synthetic talc nanoparticles. However, the other models involving D3, D4, and D5-type defects have also to be considered in order to explain the presence of the 
three $\mathrm{Na}$ environments in the samples. Weiss et al. ${ }^{54}$ have shown that deshielding of ${ }^{29} \mathrm{Si}$ chemical shift for $\mathrm{Q}^{3}$ sites in 2:1 natural layered silicates is related to both structural distortions caused by mismatch of the tetrahedral and octahedral sheets and compositional variations in the octahedral sheets, while it is only weakly dependent on the nature of interlayer cations. They show linear correlations of $\mathrm{Q}^{3}$ deshielding $\Delta \delta$ with an increasing total layer charge, with for instance $\Delta \delta=4.3 \mathrm{ppm}$ when comparing talc with hectorite, in which $1 \mathrm{Mg}^{2+}$ over 6 is substituted by $\mathrm{Li}^{+}$, therefore adding as much as one electron per unit-cell. The models we propose on the basis of DFT calculations are not contradictory with these earlier findings, however localizing defects at the water/TOT interface, as well as introducing substitutions of $\mathrm{Mg}^{2+}$ not only by the very low amount of $\mathrm{Na}^{+}$available, by also by vacancies, thus charging and distorting the interfacial TOT layers, allows a consistent explanation of the observed variations with PSD for these samples.

Our experimental and simulation studies also enabled to gain insights into the chemistry of reactive surface sites composing the lateral edges of the synthetic talc particles (Figure 12, layer N). In the experimental NMR spectra, these groups are visible only on the smallest samples (ST-2H and ST-6H), particularly in ${ }^{29} \mathrm{Si}$ where $\mathrm{Q}^{2}$-type species appear circa $-86 \mathrm{ppm}$ ( $\mathrm{Si}{ }^{*} \mathrm{OH}$ groups). In the ${ }^{1} \mathrm{H}$ NMR spectra, the identification of the edges contributions is much trickier because of the absence of clear diagnostic peaks. We notably expected to observe a signal at $+1.8 \mathrm{ppm}$ for the $\mathrm{SiOH}^{*}$ groups but the experimental approach showed no evidence. This is particularly surprising considering the intensity of the $\mathrm{Q}^{2}$-type signal whose species are much less sensitive than $\mathrm{H}$ atoms. However, since the DFT calculations as well as ${ }^{1} \mathrm{H}-{ }^{1} \mathrm{H}$ double quanta experiments (Figure S7) have confirmed the presence of $\mathrm{SiOH}$ groups on the particles edges, these groups exist but may be masked for some reasons. One explanation could be related to their mobility and interaction with water molecules which decrease the intensity of the signal and widen the resonance frequency range (wide signal of low amplitude between 1.2-2.0 ppm). 
Another possibility would involve the presence of another component located inside the $\mathrm{Q}^{2}$ peak at -86 ppm so that the proportion of silanols initially thought is much smaller. In this case, some synthesis residues like silicates oligomers could be contemplated because they use to form rapidly during synthesis processes and to resonate in this frequency range. ${ }^{44-47}$ Other edges contributions were also pointed out through DFT in the ${ }^{1} \mathrm{H}$ spectrum: $\mathrm{Mg}-\mathrm{OH}_{2}$ and $\mathrm{Mg}_{2} \mathrm{OH}$ groups. These species had already been described in infrared spectroscopy on synthetic talc particles ${ }^{48}$, but it is the first time they are clearly identified in ${ }^{1} \mathrm{H}$ NMR. According to the DFT results, the $\mathrm{Mg}-\mathrm{OH}_{2}{ }_{2}$ groups resonate at the same frequency than all of the other types of water present in the samples, that is to say at around 4.0-5.0 ppm (adsorbed water and structural water molecules as previously described). Concerning the $\mathrm{Mg}_{2} \mathrm{OH}^{*}$ groups, they resonate at a distinct chemical shift depending on the surface terminations regarded: around $+1.5 \mathrm{ppm}$ for the $\{130\}$ plane (not observed) and +0.8 ppm for the $\{100\}$ plane (observed, see Figure $2 a$ ).

\section{Application to Nanotalc Size and Aspect Ratio Determinations on the Basis of}

NMR Signals. We have found that NMR signals recorded for nanotalc samples present deviations from those recorded for micronic natural talc: in particular correlated supplementary ${ }^{1} \mathrm{H}$ peaks centered on $+0.2 \mathrm{ppm}$ and ${ }^{29} \mathrm{Si}$ peaks centered on $-95.5 \mathrm{ppm}$ appear in the former aside the $+0.4 \mathrm{ppm}$ and $-98 \mathrm{ppm}$ peaks respectively observed in the latter (Figure 2). Moreover nanotalc samples also present low amplitude broad peaks ${ }^{29} \mathrm{Si}$ centered on $-86 \mathrm{ppm}$, and ${ }^{1} \mathrm{H}$ peaks centered on +4.0 and $+1.8 \mathrm{ppm}$ (these two being hardly seen for the reasons given above) compatible with the predictions for edge surfaces presented in the previous section. Since the contributions of these extra peaks relative to those featured by micronic talc decrease with increasing crystallinity and particle size as the time scale of synthesis increases from hours to months it is natural to interpret them as signatures of surface atoms conveying a quantitative information on crystallite average morphologies in the samples: For instance, the ${ }^{29} \mathrm{Si}$ contribution centered on $-95 \mathrm{ppm}$ signs the occurrence of perturbed $\mathrm{Q}^{3}$ sites at the water/basal 
planes interfaces $\left(\mathrm{PQ}^{3}\right)$, while that centered on $-86 \mathrm{ppm}$ signs the contribution of $\mathrm{Q}^{2}$ sites at edge planes (confirmed by DFT, Table 5). Knowing the areal densities of $\mathrm{Q}^{2}$ and $\mathrm{PQ}^{3}$ sites, and the volumic density of normal $\mathrm{Q}^{3}$ sites in the "bulk" it is possible to model the full ${ }^{29} \mathrm{Si}$ signal assuming areas are proportional to atoms concentrations as usual in NMR, and introducing as parameters the average dimensions of crystallites $\mathrm{L}_{1}, \mathrm{~L}_{2}$, and e as defined in a previous section. Next, these dimensions can be extracted from the experimental chemical shift profiles by minimizing an objective function. To that end we propose the following formulation:

Assuming that atoms $X_{i}$ present distinct chemical shifts in surface and in volume of a solid particle expressing $P$ surfaces in its morphology. Let the latter be distinguished by the superscript $j, j=1, \ldots P$. The number $N_{i}^{j}$ of atoms $i$ in surface $j$ is:

$$
N_{i}^{j}=\rho_{i}^{j} S^{j}
$$

While the total number $N_{i}^{V}$ of atoms $i$ in the particle is:

$$
N_{i}^{V}=\rho_{i}^{V} V
$$

Where $\rho_{i}^{j}$ is the areal density of atoms $i$ for surface $j$, of area $S^{j}, \rho_{i}^{V}$ the number of atoms $i$ per unit volume, and $V$ the volume of the particle. Then, assuming that NMR signals are proportional to atomic concentrations of nuclei in the sample probed, the relative contribution $r_{i}^{j}$ of surface $j$ to the integral signal for nucleus $i$ is:

$$
r_{i}^{j}=\frac{I_{i}^{j}}{I_{i}^{V}+\sum_{j} I_{i}^{j}}=\frac{N_{i}^{j}}{N_{i}^{V}}
$$

Where $I_{i}^{j}$ is the integral of the NMR signal for nucleus $i$ and surface $j$, and $I_{i}^{V}$ the integral of the NMR signal for nucleus $i$ and volume $V$. The relative contribution of nuclei $i$ in bulk belonging to no surface is: 


$$
r_{i}^{B}=\frac{N_{i}^{V}-\sum_{j} N_{i}^{j}}{N_{i}^{V}}=1-\sum_{j} r_{i}^{j}
$$

Notice that assuming $\mathrm{PQ}^{3}$ is mostly determined by defects of type [D6] and [D5] in interfacial TOT layers (cf Table 3), which affects Si nuclei on both sides, for the $\{001\}$ surface contributions, we have to replace equation (1) in that case by:

$$
N_{i}^{001}=2 \rho_{i}^{001} S^{001}
$$

At this point, a geometrical model of the particle, a nanocrystallite, must be introduced so as to define surfaces and their relative extensions. The equilibrium morphology, if known, can be taken as a template since it is well known that individual nanoparticles growing from large concentrations of nuclei early reach their equilibrium morphologies, and further increase in size by Ostwald ripening. ${ }^{49}$ Therefore in the case of nanotalc, we considered model particles expressing exclusively the $\{001\},\{130\}$ and $\{100\}$ facets. The particle thickness $e$, length $L_{1}$ of a $\{100\}$ facet and length $L_{2}$ of a $\{130\}$ facet, may be expressed as multiples of the bulk unitcell parameters $c, b$ and $a$ respectively:

$$
\begin{aligned}
& e=K \frac{c}{2} \\
& L_{1}=L b \\
& L_{2}=M a
\end{aligned}
$$

With $K, L, M$ integers. Notice that $K$ is the number of stacked TOT + Interlayer space layers along the $\vec{c}$ axis. Areas $S^{j}$ and volume $V$ of nanoparticles can be expressed as functions of $L_{1}$ and $L_{2}$ as:

$$
\begin{aligned}
& S^{001}=L_{2} \sqrt{3}\left(L_{2}+2 L_{1}\right) \\
& S^{130}=4 L_{2} e
\end{aligned}
$$




$$
\begin{aligned}
& S^{100}=2 L_{1} e \\
& V=\frac{S^{001}}{2} e
\end{aligned}
$$

Moreover, as mentioned in a previous section, a talc nanoparticle at equilibrium morphology in our conditions of synthesis is characterized by:

$$
\begin{aligned}
& L_{1}=8.176 e \\
& L_{2}=6.013 e
\end{aligned}
$$

The distribution of NMR signals $P_{i}^{j, V}\left(\delta_{i}\right)$ will be as usual assumed to be Lorentzian and therefore fully determined by two parameters, the peak chemical shift $\left\langle\delta_{i}^{j, V}\right\rangle$ and its full width at half maximum (FWHM) $\Gamma_{i}^{j, V}$. The superscript $j, V$ encompasses facets $j$ and volume $V$. Since the integral of the Lorentzian distribution function is equal to unity and using our definition of $I_{i}^{j, V}$ as a weight we obtain:

$$
P_{i}^{j, V}\left(\delta_{i}\right)=I_{i}^{j, V} \frac{\frac{\Gamma_{i}^{j, V}}{2 \pi}}{\left(\delta_{i}^{j}-\left\langle\delta_{i}^{j, V}\right\rangle\right)^{2}+\left(\frac{\Gamma_{i}^{j, V}}{2}\right)^{2}}
$$

So that:

$$
\sum_{j, V} \int P_{i}^{j, V}\left(\delta_{i}\right)=1
$$

The densities $\rho_{i}^{j}$ and $\rho_{i}^{V}$ are deduced from our knowledge of the talc unit-cell (see previous section). The peak chemical shifts $\left\langle\delta_{i}^{j, V}\right\rangle$ can be either identified to the DFT predictions for surfaces $j$ or to the experimental values used directly and compared to the DFT predictions. Parameters FWHM $\Gamma_{i}^{j, V}$ should sum up an experiment dependent contribution $\Gamma_{i, e}^{j, V}$ and an intrinsic contribution $\Gamma_{i}^{j, V, I}$ reflecting the diversity of chemical environments for nuclei at the considered positions as predicted by DFT. 
In order to compare this model to our experiments we choose to minimize objective functions defined as:

$$
O_{i}=\sum_{i, k}\left(\sum_{j, V} P_{i}^{j, V}\left(\delta_{i, k}\right)-S_{i}^{E x p}\left(\delta_{i, k}\right)\right)^{2}
$$

Where the subscript $k$ labels an element of the set of chemical shifts $\delta_{i, k}$ corresponding to the discretization of the experimental signal into the set $S_{i}^{E x p}\left(\delta_{i, k}\right)$ of S values, $k=1, \ldots S$. For each sample investigated, this objective function is minimized with respect to $e$ and $\Gamma_{i, e}^{V}$, assuming $\Gamma_{i, e}^{j, V}=\Gamma_{i, e}^{V} \forall j$, all other parameters in the model being fixed by DFT predictions. The goodness of the fit can be evaluated by the root mean square deviation (rmsd):

$$
r m s d=\sqrt{\frac{\min \left(o_{i}\right)}{s}}
$$

Table 6 summarizes the results of these optimizations, and the corresponding ${ }^{29} \mathrm{Si} \mathrm{NMR}$ profiles are presented on Figure 13, in comparison to the experimental profiles already presented in Figure 2. The detailed decomposed profiles are given in Supplementary Information, Figure S8.

Table 6. Identification of Nanotalc Morphologies from Experimental ${ }^{29}$ Si NMR Signals. ${ }^{a}$

\begin{tabular}{lllllllllll}
\multicolumn{1}{c}{ sample } & $\mathrm{t}$ & $\mathrm{rmsd} \times 10^{3}$ & $\Gamma_{\mathrm{Si}, \mathrm{e}}^{\mathrm{V}}$ & $\mathrm{e}_{\mathrm{NMR}}$ & $\mathrm{L}_{1}$ & $\mathrm{~L}_{2}$ & $\mathrm{~K}$ & $\mathrm{~L}$ & $\mathrm{M}$ & $\mathrm{e}_{\mathrm{XRD}}$ \\
ST-2H & 2 & 2.15 & 2.22 & 3.35 & 27 & 20 & 2 & 46 & 38 & 14.5 \\
ST-6H & 6 & 1.96 & 2.23 & 5.57 & 46 & 33 & 3 & 77 & 64 & 15.4 \\
ST-1D & 24 & 1.43 & 2.17 & 7.94 & 65 & 48 & 4 & 110 & 91 & 22.8 \\
ST-2W & 336 & 1.08 & 2.03 & 13.57 & 111 & 82 & 8 & 188 & 155 & 35.9 \\
ST-1M & 720 & 3.20 & 0.93 & 17.10 & 140 & 103 & 10 & 237 & 195 & 54.4 \\
ST-2W-F & 336 & 7.65 & 1.08 & 10.56 & 86 & 63 & 6 & 146 & 121 & 17.0 \\
ST-2W-C & 336 & 8.26 & 0.82 & 23.78 & 194 & 143 & 13 & 329 & 272 & 55.2
\end{tabular}

${ }^{a}$ Inputs: $\mathrm{Q}^{2}, \mathrm{PQ}^{3}$ and $\mathrm{Q}^{3}{ }^{29} \mathrm{Si}$ signals recorded experimentally peaking at $-86,-95.5$ and -98.2 ppm respectively, areal and volumic densities reported in the previous sections, $\rho_{S i}^{001}=$ 8.356 Si. nm $m^{-2}, \rho_{S i}^{130}=2.362$ Si. $n m^{-2}, \rho_{S i}^{100}=2.337$ Si. $\mathrm{nm}^{-2}$ and $\rho_{S i}^{V}=18.735$ Si. $\mathrm{nm}^{-3}$, and from Table 3 and 5, intrinsic FWHM values $\Gamma_{S i}^{001, I}=1 \mathrm{ppm}, \Gamma_{S i}^{130, I}=0.2 \mathrm{ppm}, \Gamma_{S i}^{100, I}=$ 
$1 \mathrm{ppm}$. Outputs are the experimental FWHM $\Gamma_{S i, e}^{V}$, in ppm, and the average thickness $e_{N M R}$. Lengths $L_{1}, L_{2}$ derived from equations (13) and (14) and integers $K, L, M$ rounded up from equations (6), (7), (8) are also reported. The last column reports for comparison $e_{X R D}$ resulting from a Debye-Scherrer analysis of the (001) lines of the experimental XRD diffractograms shown on Figure 1. Lengths $e_{N M R}, L_{1}, L_{2}$, and $e_{X R D}$ in nm. Synthesis duration time $t$ in hours is recalled in the first column.
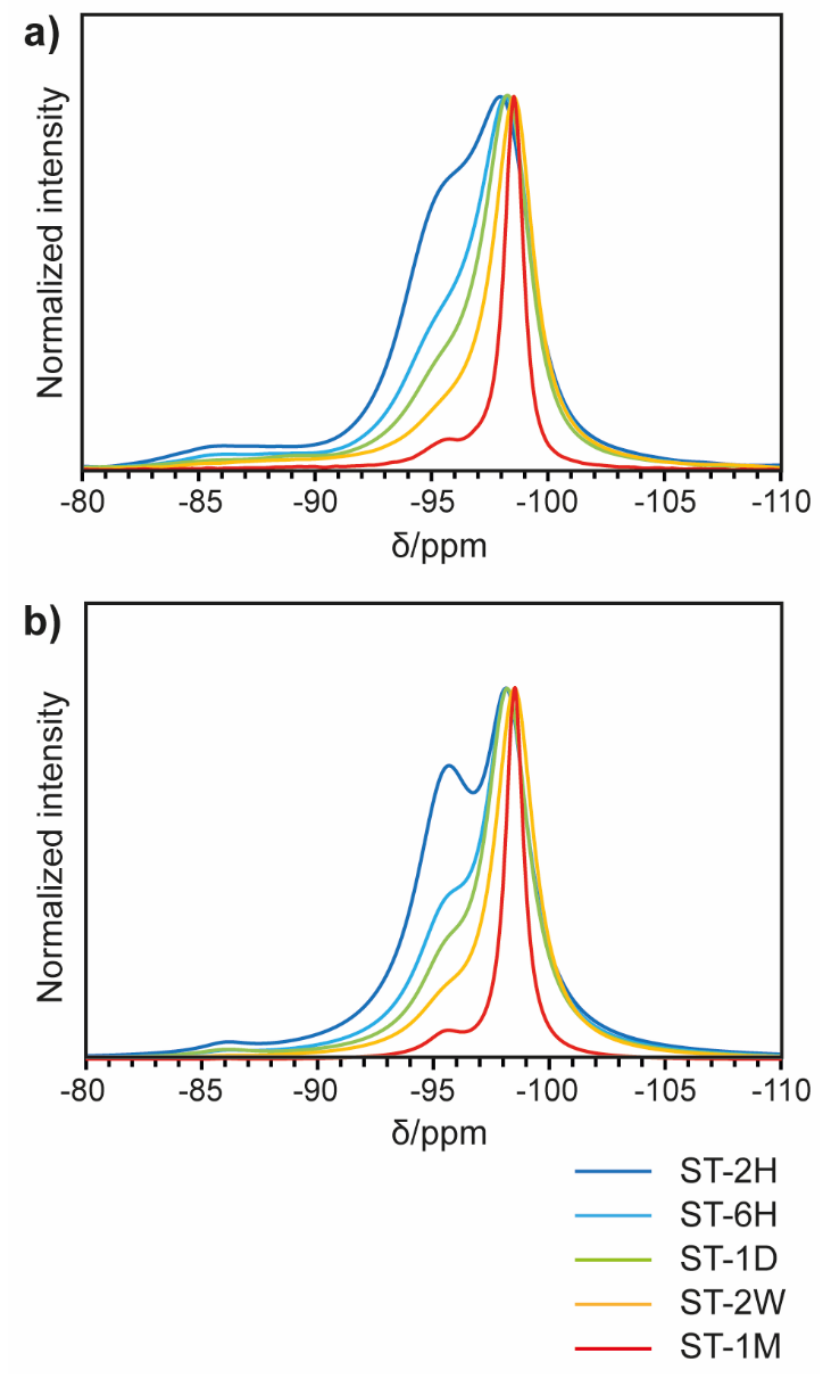

Figure 13 (a) Experiments (same as on Figure 2) and (b) simulated ${ }^{29} \mathrm{Si}$ NMR signals for the nano-sized talc samples of this study according to the parameters displayed in Table 6. 
Since experiments record average dimensions, we allowed thicknesses $e$ to take any real value, instead of constraining it to remain an integer multiple of one TOT+IS layer thickness as specified in equation (6). We report however in Table 6 for $K, L, M$ the closest integers to the real values resulting from the fits.

Table 6 reveals that our interpretation of ${ }^{29} \mathrm{Si} \mathrm{NMR} \mathrm{signals} \mathrm{in} \mathrm{terms} \mathrm{of} \mathrm{morphology} \mathrm{and}$ size does reflects the expected regular increase of average nanoparticle sizes with increasing synthesis time. The separation in size resulting from centrifugation of sample ST-2W is also correctly recorded. The discrepancy with Debye-Scherrer analysis of XRD (001) line is however striking: actually, both estimates are closely linearly correlated, as shown on Figure 14. In what follows, we propose an interpretation of this discrepancy.



Figure 14. Correlation obtained between $e_{X R D}$ and $e_{N M R}$ for samples ST-2H to ST-1M.

Both NMR and XRD techniques record averages of actual distributions in sizes, but are blind for different ranges of sizes: XRD is blind for the smallest domains of coherence, while NMR becomes blind when surface/volume ratios fall below some thresholds. Signals over noise ratios can be expressed straightforwardly for the detection of talc nanoparticles thickness $e$ 
along the $\vec{c}$ axis. Indeed, in the NMR case, the exploitable signals $S(e)$ is proportional to $I_{i}^{001}$, therefore to $\frac{1}{e}$, while in the XRD case, $S(e)$ is inversely proportional to the (001) line FWHM, therefore proportional to $e$. Ratios of signals $S(e)$ to noises $N$ can then be expressed as:

$\frac{S(e)}{N}_{N M R}=\frac{e_{M}}{e}$

and:

$\frac{S(e)}{N}_{X R D}=\frac{e}{e_{m}}$

Where $e_{M}$ and $e_{m}$ are respectively the maximum thickness detectable by NMR, and the minimum thickness detectable by XRD, which in both cases correspond to $\frac{S(e)}{N}=1$.

Next, it is well known that nanoparticles sizes are generally distributed according to a Log-normal law. ${ }^{50,51}$ Assuming that it is the case for nanotalc prepared according to our synthesis protocol, the real Particle Size Distribution (PSD) can be expressed as function of $e$ as:

$$
\wp(e)=\frac{1}{e \sigma \sqrt{2 \pi}} \exp \left(-\frac{(\ln e-\mu)^{2}}{2 \sigma^{2}}\right)
$$

Where $\sigma$ is the standard deviation and $\mu$ the mean of $\ln e$. The mean of $e$ in the same unit is expressed by:

$$
\langle e\rangle=\exp \left(\mu+\frac{\sigma^{2}}{2}\right)
$$

Then, according to the definitions given above, $e_{N M R}$ and $e_{X R D}$ turn out to be respectively the conditional expectations $E\left[e / e<e_{M}\right]$ and $E\left[e / e>e_{m}\right]$ which have the following analytical expressions: 
$e_{N M R=<e} \frac{\Phi\left[\frac{\ln e_{M}-\mu-\sigma^{2}}{\sigma}\right]}{\Phi\left[\frac{\ln e_{M^{-}}}{\sigma}\right]}$

$e_{X R D=<e>} \frac{\Phi\left[\frac{-\ln e_{m}+\mu+\sigma^{2}}{\sigma}\right]}{1-\Phi\left[\frac{\ln e_{m}-\mu}{\sigma}\right]}$

With $\Phi$ the normal cumulative distribution function, expressed by:

$$
\Phi(x)=\frac{1}{2}\left[1+\operatorname{erf}\left(\frac{x}{\sqrt{2}}\right)\right]
$$

We recover therefore for a Log-normal distributed PSD the proportionality observed on Figure 14.

Moreover, proper estimates of $e_{M}$ and $e_{m}$ in the conditions of measurements allow solving the system of equations (23) and (24) for $\sigma$ and $\mu$ against the observed $e_{N M R}$ and $e_{X R D}$, hence determining the real PSD $\wp(e)$ for each sample. From the analysis of experimental signals to noise ratios, and the independent information provided by BET areas measurements (see below) we have obtained $e_{M}=17.7 \mathrm{~nm}$ and $e_{m}=8.9 \mathrm{~nm}$. Table 7 reports the resulting numerical solutions for the various samples investigated, and Figures 15 and 16 the corresponding Lognormal PSDs.

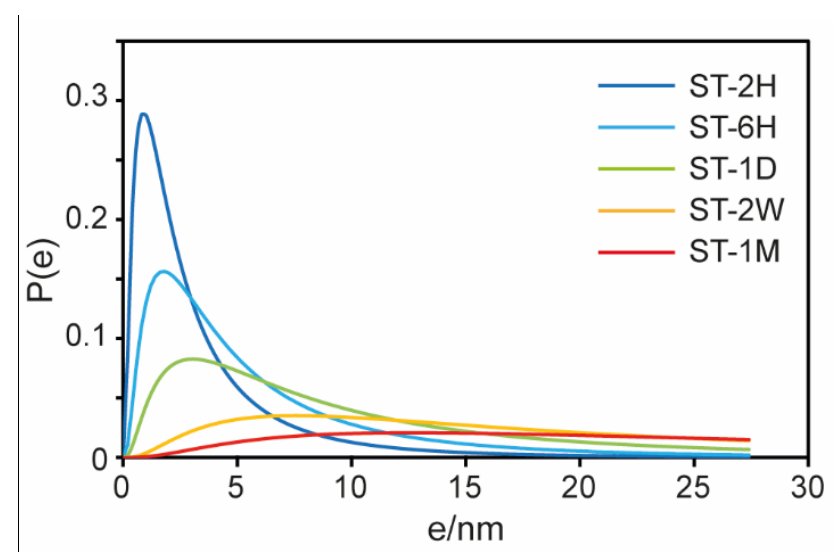

Figure 15. Log-normal Particle Size Distributions corresponding to parameters reported in Table 7 for increasing time of synthesis. 




Figure 16. Log-normal Particle Size Distributions corresponding to parameters reported in Table 7 showing the effect of separation by centrifugation.

Table 7. Parameters of Log-Normal Pore Size Distributions Obtained by Solving Numerically Equations (23) and (24) of the Conditional Expectations $E\left[e / e<e_{M}\right]$ and $E\left[e / e>e_{m}\right]$ for $e_{M}=17.7 \mathrm{~nm}, e_{m}=8.9 \mathrm{~nm}$, and the Values of $e_{N M R}$ and $e_{X R D}$ Reported in Table 6. $t$ in hours, all other columns in $\mathbf{n m}$. SAth is the predicted according to equation (26), and SAobs measured surface area in $m^{2} \cdot g^{-1} \cdot\left({ }^{*}\right)$ Reproduced twice at 1 week interval.

\begin{tabular}{llllccccc}
\multicolumn{1}{c}{ sample } & $\mathrm{t}$ & $\mathrm{e}_{\mathrm{NMR}}$ & $\mathrm{e}_{\mathrm{XRD}}$ & $\sigma$ & $\mu$ & $\langle\mathrm{e}\rangle$ & SAth & SAobs \\
ST-2H & 2 & 3.35 & 14.5 & 0.973 & 0.847 & 3.74 & 221 & 218 \\
ST-6H & 6 & 5.57 & 15.4 & 0.936 & 1.481 & 6.81 & 121 & 124 \\
ST-1D & 24 & 7.94 & 22.8 & 0.972 & 2.151 & 13.79 & 60 & $74\left(^{*}\right)$ \\
ST-2W & 336 & 13.57 & 35.9 & 0.945 & 2.967 & 30.37 & 27 & 36 \\
ST-1M & 720 & 17.10 & 54.4 & 0.949 & 3.473 & 50.58 & 16 & 29 \\
ST-2W-F & 336 & 10.56 & 17.0 & 0.866 & 2.172 & 12.77 & 65 & 59 \\
ST-2W-C & 336 & 23.78 & 55.2 & 0.917 & 3.541 & 52.55 & 16 & 26
\end{tabular}

Inspection of Table 7 reveals that $\sigma$ and $\mu$ and $\langle e\rangle$ evolve continuously with increasing time of synthesis: $\sigma$ is fluctuating slightly around an average value, while $\mu$ increases logarithmically, and $\langle e\rangle$ increases according to a power law (see Figures S9a-b). The centrifugal 
separation of sample ST-2W into a fine (ST-2W-F) and a coarse (ST-2W-C) fraction results as expected in PSDs and $\langle e\rangle$ "bracketing" that of the initial sample. Finally, $e_{N M R}$ underestimates, and $e_{X R D}$ overestimates $\langle e\rangle$, but the former is a better estimate at short synthesis times, or $\langle e\rangle<$ $10 \mathrm{~nm}$, and the latter a better estimate at long synthesis times or $\langle e\rangle>20 \mathrm{~nm}$.

Since the surface area of a nanotalc particle at equilibrium is inversely proportional to $e$, the surface area $S A$ of an ensemble of Log-normal distributed nanotalc particles is proportional to the inverse mean of this PSD, i.e.:

$$
S A=\frac{\chi}{d} \exp \left(-\frac{\sigma^{2}}{2}-\mu\right)=\frac{\chi}{<e>d}
$$

Where $\chi$ is an adimensional shape factor easily deduced from the combination of


$S A$ are given in the $8^{\text {th }}$ column of Table 7 , to be compared to experimental values reported in the last column. Our first estimates for $e_{m}$ and $e_{M}$ based on the sole consideration of $S(e)$ to noises $N$ lead us to 6 and $18 \mathrm{~nm}$ respectively, but then a systematic deviation by $15 \%$ of predicted versus experimental $S A$ was obtained. We decided therefore to use this extra information from BET measurements, and constrained this deviation to be minimal in the numerical solution of equations (23) and (24), allowing $e_{m}$ and $e_{M}$ to vary. The final solution led to the slightly corrected values $e_{m}=8.9 \mathrm{~nm}$ and $e_{M}=17.7 \mathrm{~nm}$.

Figure 17 presents the parity diagram thus achieved between predicted and experimental $S A$ as listed in Table 6 above. The regression line has a slope of 0.9809 , and the squared coefficient of correlation is 0.9829 , almost undistinguishable from the first bisector. 


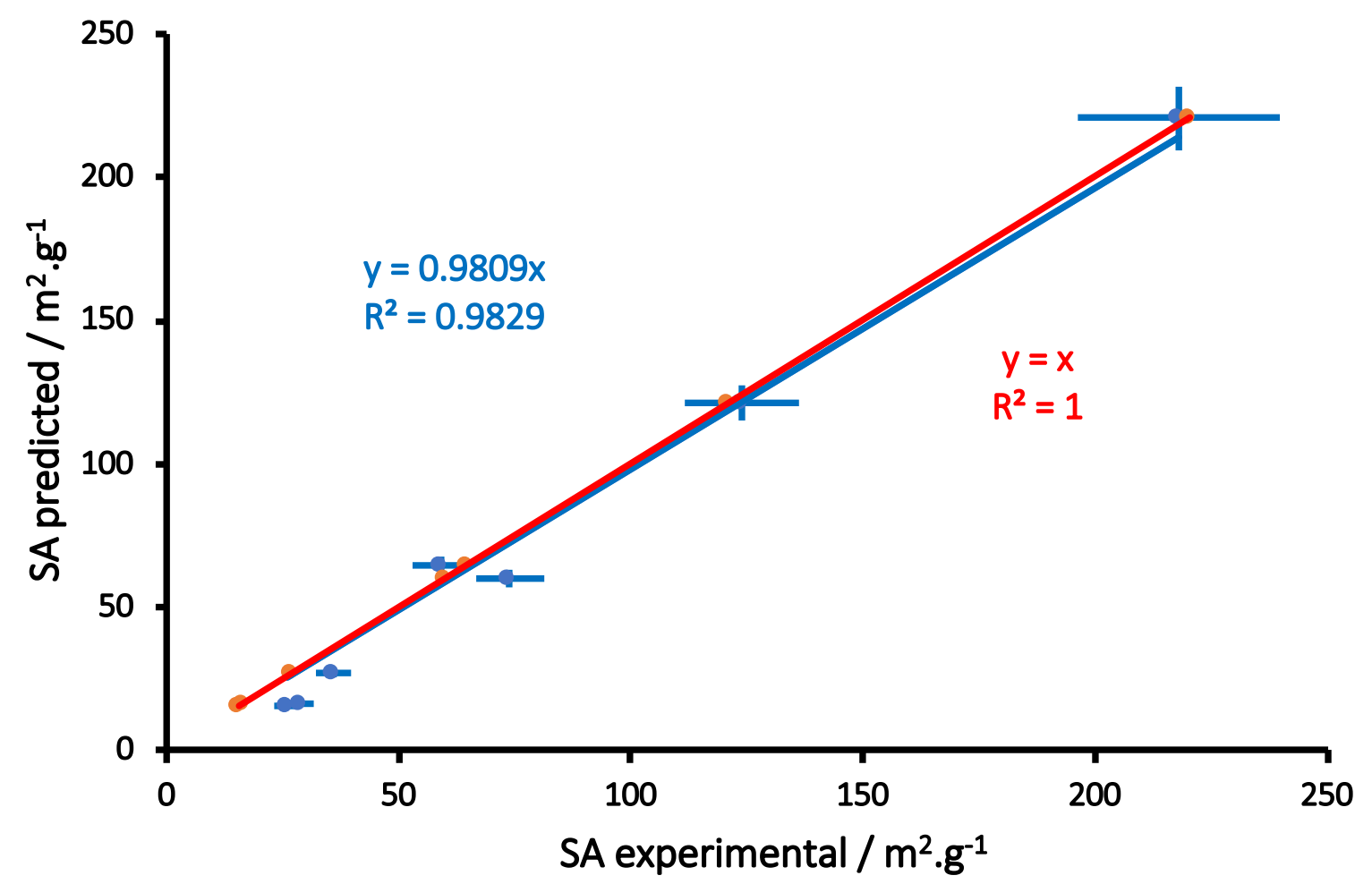

Figure 17. Correlation between predicted surface area from equation (26) and experimental measurements (blue dots and blue line). For the latter, a 10\% relative error is assumed as usually expected for BET.

Finally, let us compare these results with the particle sizes determined by DLS: one should bear in mind that DLS actually measures exponential decays of light scattering signals related to diffusion coefficients of scatterers. The latter as interpreted as particle sizes through the Stokes-Einstein equation, however, these sizes are actually hydrodynamic radii, assimilated to radii of gyration. We have computed as function of $L_{1}, L_{2}$ and $e$ the radius of gyration of an equilibrium talc nanoparticle such as represented on Figure 9.

The algorithm is classical, involving the calculation of the moments of inertia $I_{i}$ for $i=$ $x, y, z$ where $x, y, z$ denote the principal symmetry axes crossing at the center of gravity. Details of this calculation are provided as Supporting Calculation 3-1 in Supporting Information pages 
S16-S21. Moreover, using equations (13) and (14) for a hydrated talc particle at morphology equilibrium in our synthesis conditions we predict:

$$
R_{H}=R_{g}=3.464 e
$$

We provide on Figure 18 the observed linear correlation between the experimental mean hydrodynamic diameters measured by DLS and $\langle e>$ : the slope of 3.567 and coefficient of correlation $R^{2}=0.9662$ indicate an excellent agreement with the theoretical prediction, furnishing a nice proof that individual talc nanoparticles have reached equilibrium morphology with equations (13) and (14) verified within better than 0.5 with an error margin less than $3 \%$. Moreover, an analysis of the distributions in numbers of hydrodynamic radii provided by the Laplace-Padé analysis of DLS experiments also restitute the expected Log-normal distributions (see $\mathrm{S} 10)$.



Figure 18. Correlation between the mean $R_{H}$ obtained by DLS and $\langle e\rangle$ (in blue) compared to the predicted correlation (in orange) for talc nanoparticles at equilibrium morphology in presence of water at synthesis temperature. 
Finally, it is worth mentioning that it would be quite insightful to use our series of samples in order to benchmark further the combined NMR/XRD approach we propose against well established but far less accessible wave scattering methods like for instance SANS and SAXS. This would however imply undertaking a quite extensive supplementary program beyond the resources available for the present study.

\section{CONCLUSIONS}

Combining experimental characterizations by solid-state multi-nuclear NMR, XRD, DLS, SEM, B.E.T surface area measurement, and first principles (DFT) simulations, we report for a set of talc nanoparticles prepared at iso-conditions and synthesis times varying between 2 hours and 1 month:

(1) A complete consistent assignation of observed ${ }^{29} \mathrm{Si},{ }^{1} \mathrm{H},{ }^{25} \mathrm{Mg}$ and ${ }^{23} \mathrm{Na}$ NMR chemical shifts of synthetic talc nanoparticles based on a strong experimental study coupled with microscopic models of the various surface and bulk configurations.

(2) The identification of surface reactive sites and defective layers which may explain the peculiar physico-chemical properties encountered in the nano-sized synthetic talc particles.

(3) The successful decomposition of ${ }^{29} \mathrm{Si}$ chemical shifts profiles in terms of distinct Lorentzian contributions of nuclei at surfaces and in the bulk, reflecting the morphology and average dimensions of nanoparticles at equilibrium morphology in presence of water and synthesis temperature $(\sim 600 \mathrm{~K})$ for each sample.

(4) An identification of the respective windows of sight in nanoparticle sizes determinations by our surface sensitive NMR approach and the Debye-Scherrer analysis of XRD lines.

(5) The reconciliation of PSD and morphology determinations by NMR, XRD, B.E.T and DLS assuming Log-normal distributions in number. 
We expect these findings will prove helpful in the precise control of synthetic talc nanoparticles geometric and physico-chemical properties, with wide range applications in colloid and surface science and technologies. We anticipate moreover fruitful transpositions of our approach to other nanoparticular systems. 


\section{AUTHORS CONTRIBUTIONS}

MP prepared and characterized the samples by NMR, XRD, SEM, DLS, and drafted the report. HT designed and performed all DFT simulations and theoretical calculations. YM, VH and MP performed together the 2D NMR characterizations and interpretations of raw NMR datas. ESG and GL measured the BET areas. MJ initiated the LRS/GET/LAMS collaboration, FM and HLP organized and planned the collaboration. PM helped the interpretation of the results. All authors were involved in numerous meetings which drove this research and allowed in depth discussions of intermediate results. All authors reviewed and discussed the final version submitted.

\section{ACKNOWLEDGMENT}

This work was partially supported by French state funds managed by the ANR within the Investissements d'Avenir programme under reference ANR-11-IDEX-0004-02, and more specifically within the framework of the Cluster of Excellence MATISSE led by Sorbonne Universités. We also thank Yannick Coppel from the Laboratoire de Chimie de Coordination of Toulouse (France) for recording the ${ }^{1} \mathrm{H}$ and ${ }^{29} \mathrm{Si}$ DP-MAS NMR spectra.

\section{SUPPORTING INFORMATION DESCRIPTION}

1 - Supporting Tables

Table S1: DLS size distribution of the series of nano-sized synthetic talc samples

\section{2 - Supporting Figures}

Figure S1: SEM images of the nano-sized talc samples with increasing crystallinity.

Figure S2: ${ }^{1} \mathrm{H}$ direct polarization MAS NMR spectrum of sodium acetate.

Figure S3: $\left\{{ }^{1} \mathrm{H}\right\}-{ }^{13} \mathrm{C}$ HETCOR spectra of ST-AcONa. 
Figure S4: Example of deconvolution of a ${ }^{1} \mathrm{H}$ DP MAS-NMR

Figure S5: Slab model for the fully hydrated (130) talc edge: (a) side view, (b) top view, (c) front view, (d) perspective view.

Figure S6: Slab model for the fully hydrated (100) talc edge: (a) side view, (b) top view, (c) front view, (d) perspective view.

Figure S7: ${ }^{1} \mathrm{H}$ DQ-SQ PC7 spectrum of ST-6H.

Figure S8: Decompositions of ${ }^{29}$ Si NMR chemical shifts profiles.

Figure S9: Variation of Log-normal talc nanoparticle size distributions parameters with synthesis time.

Figure S9a: Variation of the mean talc nanoparticle thickness with synthesis time.

Figure S9b: Variation of the log-normal distribution parameter $\mu$ with time of synthesis.

Figure S10: Example of log-normal distribution fitting DLS data of ST-2W.

3 - Supporting calculations

3-1 Calculation of the hydrodynamic radius of a talc nanocrystallite at equilibrium morphology. 


\section{REFERENCES}

(1) Waychunas, G. A.; Zhang, H. Structure, Chemistry, and Properties of Mineral Nanoparticles. Elements 2008, 4 (6), 381-387. https://doi.org/10.2113/gselements.4.6.381.

(2) Hochella, M. F.; Lower, S. K.; Maurice, P. A.; Penn, R. L.; Sahai, N.; Sparks, D. L.; Twining, B. S. Nanominerals, Mineral Nanoparticles, and Earth Systems. Science 2008, 319 (5870), 1631-1635. https://doi.org/10.1126/science.1141134.

(3) Caraballo, M. A.; Michel, F. M.; Hochella, M. F. The Rapid Expansion of Environmental Mineralogy in Unconventional Ways: Beyond the Accepted Definition of a Mineral, the Latest Technology, and Using Nature as Our Guide. Am. Mineral. 2015, 100 (1), 14-25. https://doi.org/10.2138/am-2015-4749.

(4) Madden, A. S.; Hochella, M. F. A Test of Geochemical Reactivity as a Function of Mineral Size: Manganese Oxidation Promoted by Hematite Nanoparticles. Geochim. Cosmochim. Acta 2005, 69 (2), 389-398. https://doi.org/10.1016/j.gca.2004.06.035.

(5) Anschutz, A. J. Reduction of Crystalline Iron(III) Oxyhydroxides Using Hydroquinone: Influence of Phase and Particle Size. Geochem. Trans. 2005, 6 (3), 60. https://doi.org/10.1063/1.2037887.

(6) Madden, A. S.; Hochella, M. F.; Luxton, T. P. Insights for Size-Dependent Reactivity of Hematite Nanomineral Surfaces through Cu2+ Sorption. Geochim. Cosmochim. Acta 2006, 70 (16), 4095-4104. https://doi.org/10.1016/j.gca.2006.06.1366.

(7) Hochella, M. F. Nanogeoscience: From Origins to Cutting-Edge Applications. Elements 2008, 4 (6), 373-379. https://doi.org/10.2113/gselements.4.6.373. 
(8) Poirier, M.; Fery-Forgues, S.; Le Roux, C.; Martin, F.; Micoud, P.; Aymonier, C. Photoluminescent hybrid organic/inorganic materials and method for preparing same. WO 2018/138153 A2, August 2, 2018.

(9) Poirier, M.; Fery-Forgues, S.; Le Roux, C.; Martin, F.; Micoud, P.; Aymonier, C. Coloured organic/inorganic hybrid materials and method for preparing same. WO 2018/138148 A1, August 2, 2018.

(10) Dumas, A.; Martin, F.; Le Roux, C.; Micoud, P.; Petit, S.; Ferrage, E.; Brendlé, J.; Grauby, O.; Greenhill-Hooper, M. Phyllosilicates Synthesis: A Way of Accessing Edges Contributions in NMR and FTIR Spectroscopies. Example of Synthetic Talc. Phys. Chem. Miner. 2013, 40 (4), 361-373. https://doi.org/10.1007/s00269-013-0577-5.

(11) Dumas, A.; Claverie, M.; Slostowski, C.; Aubert, G.; Careme, C.; Le Roux, C.; Micoud, P.; Martin, F.; Aymonier, C. Fast-Geomimicking Using Chemistry in Supercritical Water. Angew. Chem. Int. Ed. 2016, 55 (34), 9868-9871. https://doi.org/10.1002/anie.201604096.

(12) Dias, G.; Prado, M.; Ligabue, R.; Poirier, M.; Le Roux, C.; Micoud, P.; Martin, F.; Einloft, S. Hybrid Pu/Synthetic Talc/Organic Clay Ternary Nanocomposites: Thermal, Mechanical and Morphological Properties. Polym. Polym. Compos. 2018, 26 (2), 127.

(13) Dias, G.; Prado, M.; Ligabue, R.; Poirier, M.; Le Roux, C.; Martin, F.; Fery-Forgues, S.; Einloft, S. Synthetic Talc as a New Platform for Producing Fluorescent Clay Polyurethane Nanocomposites. Appl. Clay Sci. 2018, 158, 37-45. https://doi.org/10.1016/j.clay.2018.03.012.

(14) Yousfi, M.; Livi, S.; Dumas, A.; Le Roux, C.; Crépin-Leblond, J.; Greenhill-Hooper, M.; Duchet-Rumeau, J. Use of New Synthetic Talc as Reinforcing Nanofillers for Polypropylene and Polyamide 6 Systems: Thermal and Mechanical Properties. J. Colloid Interface Sci. 2013, 403, 29-42. https://doi.org/10.1016/j.jcis.2013.04.019. 
(15) Yousfi, M.; Livi, S.; Dumas, A.; Crépin-Leblond, J.; Greenhill-Hooper, M.; DuchetRumeau, J. Compatibilization of Polypropylene/Polyamide 6 Blends Using New Synthetic Nanosized Talc Fillers: Morphology, Thermal, and Mechanical Properties. J. Appl. Polym. Sci. 2014, 131 (13), 40453. https://doi.org/10.1002/app.40453.

(16) Yousfi, M.; Livi, S.; Dumas, A.; Crépin-Leblond, J.; Greenhill-Hooper, M.; DuchetRumeau, J. Ionic Compatibilization of Polypropylene/Polyamide 6 Blends Using an Ionic Liquids/Nanotalc Filler Combination: Morphology, Thermal and Mechanical Properties. RSC Adv. 2015, 5 (57), 46197-46205. https://doi.org/10.1039/C5RA00816F.

(17) Claverie, M.; Dumas, A.; Carême, C.; Poirier, M.; Le Roux, C.; Micoud, P.; Martin, F.; Aymonier, C. Synthetic Talc and Talc-Like Structures: Preparation, Features and Applications. Chem. - Eur. J. 2018, 24 (3), 519-542. https://doi.org/10.1002/chem.201702763.

(18) Martin, F.; Ferrage, E.; Petit, S.; de Parseval, P.; Delmotte, L.; Ferret, J.; Arseguel, D.; Salvi, S. Fine-Probing the Crystal-Chemistry of Talc by MAS-NMR Spectroscopy. Eur. J. Mineral. 2006, 18 (5), 641-651. https://doi.org/10.1127/0935-1221/2006/0018-0641.

(19) Oldfield, E.; Kinsey, R. A.; Smith, K. A.; Nichols, J. A.; Kirkpatrick, R. J. HighResolution NMR of Inorganic Solids. Influence of Magnetic Centers on Magic-Angle SampleSpinning Lineshapes in Some Natural Aluminosilicates. J. Magn. Reson. 1969 1983, 51 (2), $325-329$.

(20) Thompson, J. G. 29Si and 27Al Nuclear Magnetic Resonance Spectroscopy of 2: 1 Clay Minerals. Clay Miner. 1984, 19, 229-236.

(21) Morris, H. D.; Bank, S.; Ellis, P. D. Aluminum-27 NMR Spectroscopy of Iron-Bearing Montmorillonite Clays. J. Phys. Chem. 1990, 94 (7), 3121-3129. https://doi.org/10.1021/j100370a069. 
(22) Dumas, A. Elaboration de Nouveaux Procédés de Synthèse et Caractérisation de Talcs Sub-Microniques: De La Recherche Fondamentale Vers Des Applications Industrielles. PhD Thesis, Université de Toulouse, Université Toulouse III-Paul Sabatier, 2013.

(23) The MAPS Platform from SCIENOMICS (https://www.scienomics.com) Was Provided to Laboratoire de Réactivité de Surface According to Its Participation to the Scienomics Group of Scientific Excellence (SGSE).

(24) Gruner, J. W. The Crystal Structures of Talc and Pyrophyllite Locality: Hardford County, Maryland, USA. Z. Krist. 1934, 88, 412-419.

(25) Gražulis, S.; Chateigner, D.; Downs, R. T.; Yokochi, A. F. T.; Quirós, M.; Lutterotti, L.; Manakova, E.; Butkus, J.; Moeck, P.; Le Bail, A. Crystallography Open Database - an Open-Access Collection of Crystal Structures. J. Appl. Crystallogr. 2009, 42 (4), 726-729. https://doi.org/10.1107/S0021889809016690.

(26) Kresse, G.; Furthmüller, J. Efficient Iterative Schemes for Ab Initio Total-Energy Calculations Using a Plane-Wave Basis Set. Phys. Rev. B 1996, 54 (16), 11169.

(27) Perdew, J. P.; Burke, K.; Ernzerhof, M. Generalized Gradient Approximation Made Simple. Phys. Rev. Lett. 1996, 77 (18), 3865-3868.

(28) Grimme, S.; Antony, J.; Ehrlich, S.; Krieg, H. A Consistent and Accurate Ab Initio Parametrization of Density Functional Dispersion Correction (DFT-D) for the 94 Elements HPu. J. Chem. Phys. 2010, 132 (15), 154104. https://doi.org/10.1063/1.3382344.

(29) Pickard, C. J.; Mauri, F. All-Electron Magnetic Response with Pseudopotentials: NMR Chemical Shifts. Phys. Rev. B 2001, 63 (24). https://doi.org/10.1103/PhysRevB.63.245101. 
(30) Yates, J. R.; Pickard, C. J.; Mauri, F. Calculation of NMR Chemical Shifts for Extended Systems Using Ultrasoft Pseudopotentials. Phys. Rev. B 2007, 76 (2). https://doi.org/10.1103/PhysRevB.76.024401.

(31) Mayo, S. L.; Olafson, B. D.; Goddard III, W. A. DREIDING: A Generic Force Field for Molecular Simulations. J. Phys. Chem. 1990, 94 (26), 8897-8909.

(32) Brindley, G.; Brown, G. Crystal Structures of Clay Minerals and Their X-Ray Identification, Mineralogical Society.; London, 1980; Vol. 5.

(33) d'Espinose de la Caillerie, J.-B.; Aimeur, M. R.; Kortobi, Y. E.; Legrand, A. P. Water Adsorption on Pyrogenic Silica Followed By1H MAS NMR. J. Colloid Interface Sci. 1997, 194 (2), 434-439. https://doi.org/10.1006/jcis.1997.5126.

(34) Trébosc, J.; Wiench, J. W.; Huh, S.; Lin, V. S.-Y.; Pruski, M. Solid-State NMR Study of MCM-41-Type Mesoporous Silica Nanoparticles. J. Am. Chem. Soc. 2005, 127 (9), 30573068. https://doi.org/10.1021/ja043567e.

(35) Lippmaa, E.; Maegi, M.; Samoson, A.; Engelhardt, G.; Grimmer, A. R. Structural Studies of Silicates by Solid-State High-Resolution Silicon-29 NMR. J. Am. Chem. Soc. 1980, $102(15), 4889-4893$.

(36) Sanz, J.; Serratosa, J. M. Silicon-29 and Aluminum-27 High-Resolution MAS-NMR Spectra of Phyllosilicates. J. Am. Chem. Soc. 1984, 106 (17), 4790-4793.

(37) Tateyama, H.; Nishimura, S.; Tsunematsu, K.; Jinnai, K.; Adachi, Y.; Kimura, M. Synthesis of Expandable Fluorine Mica from Talc. Clays Clay Miner. 1992, 40 (2), 180-185.

(38) Mägi, M.; Lippmaa, E.; Samoson, A. Solid-State High-Resolution Silicon-29 Chemical Shifts in Silicates. J. Phys. Chem. 1984, 88, 1518-1522. 
(39) Cattaneo, A. S.; Bracco, S.; Comotti, A.; Galimberti, M.; Sozzani, P.; Eckert, H. Structural Characterization of Pristine and Modified Fluoromica Using Multinuclear SolidState NMR. J. Phys. Chem. C 2011, 115 (25), 12517-12529. https://doi.org/10.1021/jp2020676.

(40) Toulhoat, H.; Lin, L.; Brouri, D.; Krafft, J. M.; Millot, Y.; Laugel, G.; Lauron-Pernot, H. Nanosized Layered TOT Magnesium-Silicates: Equilibrium Morphologies and Surface Speciation, a Computational and Experimental Study, J. Phys. Chem. C 2019, 123, 26965-26979. https://doi.org/10.1021/acs.jpcc.9b06794.

(41) Freude, D.; Haase, J. Quadrupole Effects in Solid-State Nuclear Magnetic Resonance. In Special Applications; Pfeifer, H., Barker, P., Eds.; Diehl, P., Fluck, E., Günther, H., Kosfeld, R., Seelig, J., Series Eds.; Springer Berlin Heidelberg: Berlin, Heidelberg, 1993; Vol. 29, pp 190. https://doi.org/10.1007/978-3-642-50046-6_1.

(42) Freude, D.; Haase, J. Quadrupole Effects in Solid-State NMR, Basic Principles and Experimental Techniques for Nuclei with Half-Integer Spins. Wwwquad-Nmrde 2013.

(43) Chizallet, C.; Costentin, G.; Lauron-Pernot, H.; Che, M.; Bonhomme, C.; Maquet, J.; Delbecq, F.; Sautet, P. Study of the Structure of OH Groups on MgO by 1D and 2D 1H MAS NMR Combined with DFT Cluster Calculations. J. Phys. Chem. C 2007, 111 (49), 1827918287.

(44) Rakić, S.; Kahlenberg, V.; Weidenthaler, C.; Zibrowius, B. Structural Characterization of High-Pressure C-Na2Si2O5 by Single-Crystal Diffraction and 29Si MAS NMR. Phys. Chem. Miner. 2002, 29, 477-484. https://doi.org/10.1007/s00269-002-0259-1.

(45) Cho, H.; Felmy, A. R.; Craciun, R.; Keenum, J. P.; Shah, N.; Dixon, D. A. Solution State Structure Determination of Silicate Oligomers by ${ }^{29}$ Si NMR Spectroscopy and Molecular Modeling. J. Am. Chem. Soc. 2006, 128 (7), 2324-2335. https://doi.org/10.1021/ja0559202. 
(46) Kobera, L.; Slavík, R.; Kolousek, D.; Urbanová, M.; Kotek, J.; Brus, J. Structural Stability of Aluminosilicate Inorganic Polymers: Influence of the Preparation Procedure. Ceram.-Silik. 2011, 55 (4), 343-354.

(47) Yuan, J.; Yang, J.; Ma, H.; Liu, C.; Zhao, C. Hydrothermal Synthesis of Analcime and Hydroxycancrinite from K-Feldspar in $\mathrm{Na} 2 \mathrm{SiO} 3$ Solution: Characterization and Reaction Mechanism. RSC Adv. 2016, 6 (59), 54503-54509.

(48) Blanchard, M.; Méheut, M.; Delon, L.; Poirier, M.; Micoud, P.; Le Roux, C.; Martin, F. Infrared Spectroscopic Study of the Synthetic Mg-Ni Talc Series. Phys. Chem. Miner. 2018, 45 (9), 843-854. https://doi.org/10.1007/s00269-018-0966-x.

(49) Henry, C. R. Morphology of Supported Nanoparticles. Prog. Surf. Sci. 2005, 80 (3-4), 92-116. https://doi.org/10.1016/j.progsurf.2005.09.004.

(50) Granqvist, C. G.; Buhrman, R. A. Ultrafine Metal Particles. J. Appl. Phys. 1976, 47 (5), $2200-2219$.

(51) Datye, A. K.; Xu, Q.; Kharas, K. C.; McCarty, J. M. Particle Size Distributions in Heterogeneous Catalysts: What Do They Tell Us about the Sintering Mechanism? Catal. Today 2006, 111 (1-2), 59-67. https://doi.org/10.1016/j.cattod.2005.10.013.

(52) Purusottam, R.N.; Bodenhausen, G.; Tekely, P. Determination of sample temperature in unstable static fields by combining solid-state ${ }^{79} \mathrm{Br}$ and ${ }^{13} \mathrm{C}$ NMR. J. Magn. Reson. 2014, 246, $69-71$.

(53) Bernard, G.M.; Goyal, A.; Miskolzie, M.; McKay R.; Wu, Q.; Wasylishen, R.E.; Michaelis, W.K. Methylammonium lead chloride: A sensitive sample for an accurate NMR thermometer. J. Magn. Reson. 2017, 283, 14-21. 
(54) Weiss, C.A. Jr ; Altaner, S.P.; Kirkpatrick, R.J. High-resolution ${ }^{29}$ Si NMR spectroscopy of 2:1 layer silicates: Correlations among chemical shift, structural distortions, and chemical variations. Amer. Mineral. 1987, 72, 935-942.

TOC Graphic

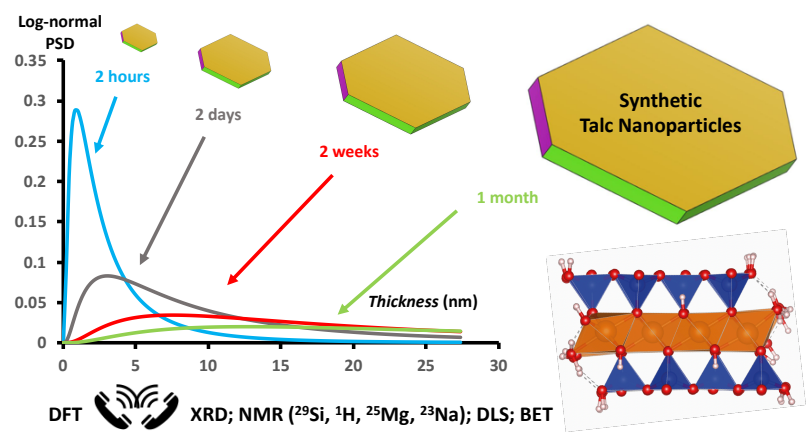

